
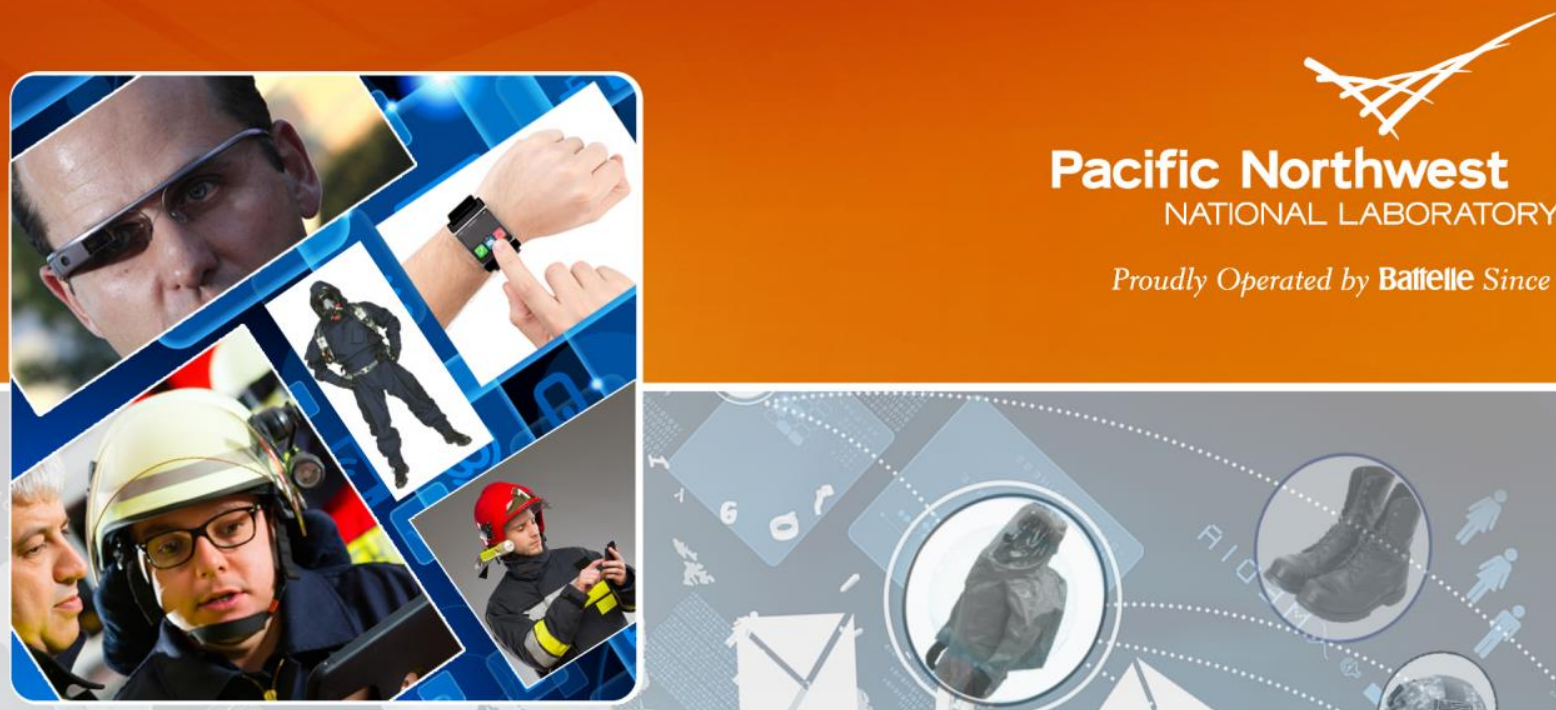

Pacific Northwest

NATIONAL LABORATORY

Proudly Operated by Balfelle Since 1965

Responder Technology
Alert (February 2015)

\title{
April 2015
}

JF Upton

SL Stein
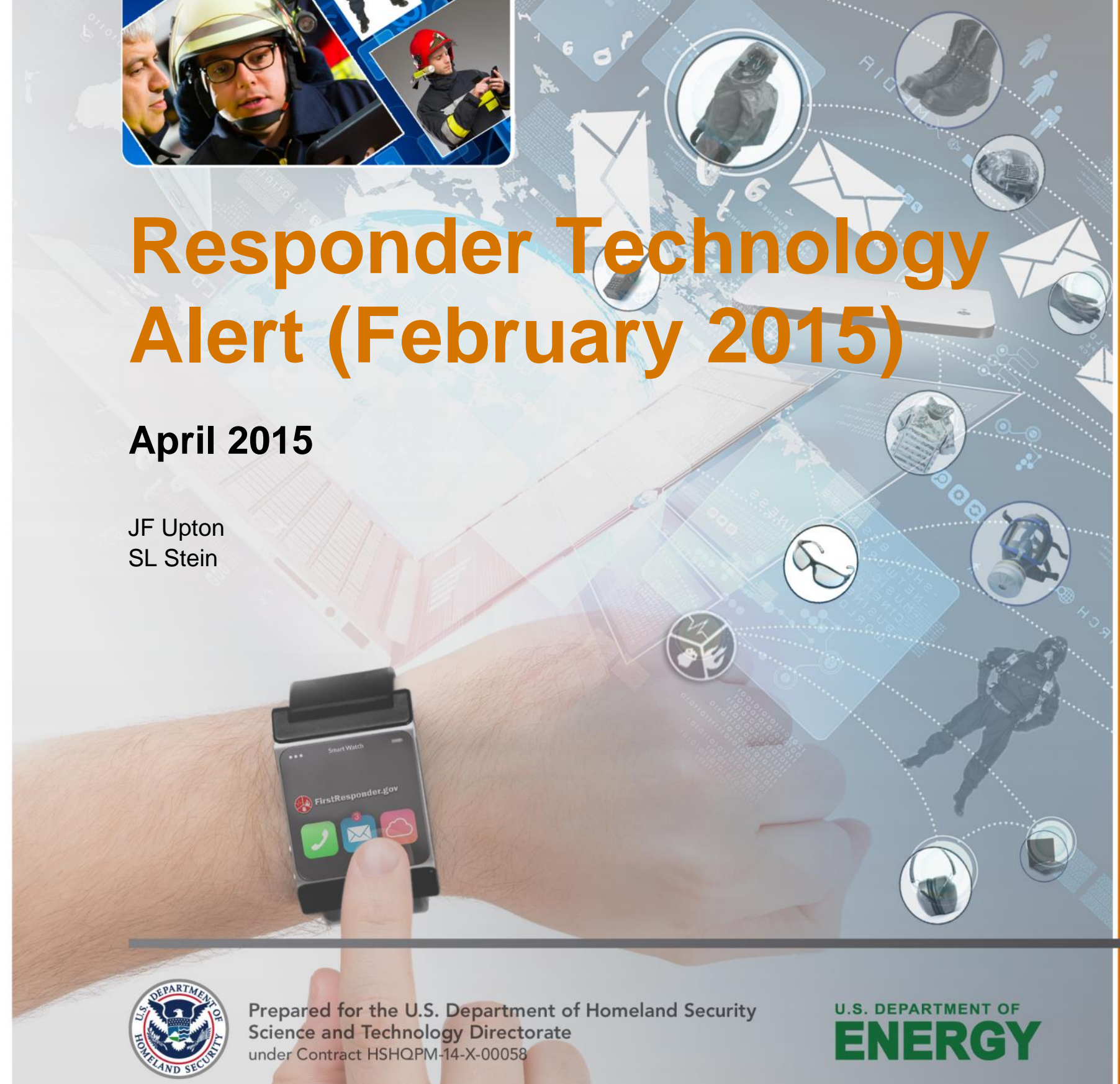

Prepared for the U.S. Department of Homeland Security
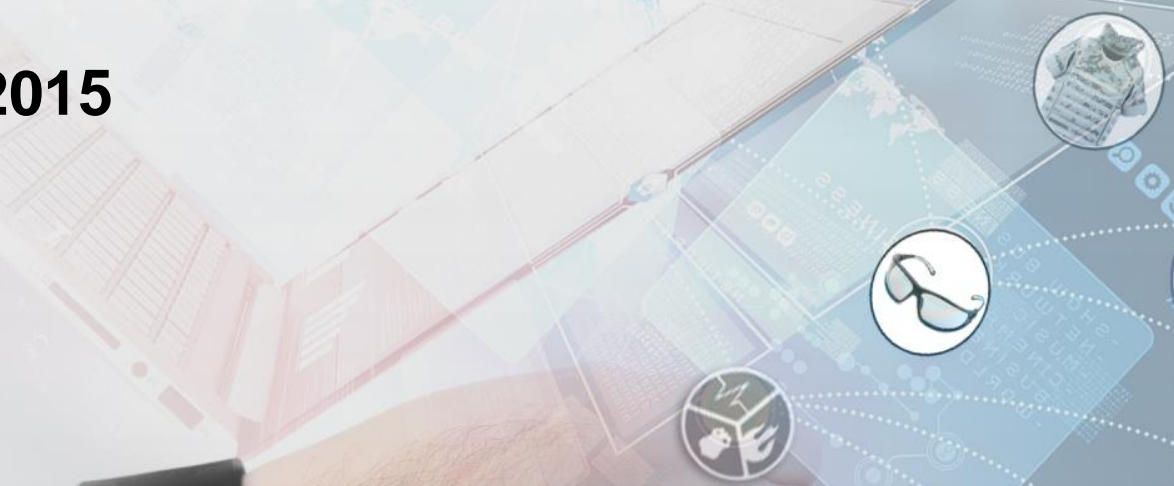

Science and Technology Directorate under Contract HSHQPM-14-X-00058 


\title{
DISCLAIMER
}

This report was prepared as an account of work sponsored by an agency of the United States Government. Neither the United States Government nor any agency thereof, nor Battelle Memorial Institute, nor any of their employees, makes any warranty, express or implied, or assumes any legal liability or responsibility for the accuracy, completeness, or usefulness of any information, apparatus, product, or process disclosed, or represents that its use would not infringe privately owned rights. Reference herein to any specific commercial product, process, or service by trade name, trademark, manufacturer, or otherwise does not necessarily constitute or imply its endorsement, recommendation, or favoring by the United States Government or any agency thereof, or Battelle Memorial Institute. The views and opinions of authors expressed herein do not necessarily state or reflect those of the United States Government or any agency thereof.

\author{
PACIFIC NORTHWEST NATIONAL LABORATORY \\ operated by \\ BATTELLE \\ for the \\ UNITED STATES DEPARTMENT OF ENERGY \\ under Contract DE-AC05-76RL01830
}

Printed in the United States of America
Available to DOE and DOE contractors from the Office of Scientific and Technical Information, P.O. Box 62, Oak Ridge, TN 37831-0062; ph: (865) 576-8401 fax: $(865) 576-5728$
email: reports $a$ adonis.osti.gov
Available to the public from the National Technical Information Service 5301 Shawnee Rd., Alexandria, VA 22312 ph: (800) 553-NTIS (6847) email: orders@ntis.gov <http://www.ntis.gov/about/form.aspx> Online ordering: http://www.ntis.gov




\section{Responder Technology Alert (February 2015)}

JF Upton

SL Stein

April 2015

Prepared for the Department of Homeland Security Science and Technology Directorate under Contract HSHQPM-14-X-00058.

Pacific Northwest National Laboratory Richland, Washington 99352 



\section{Contents}

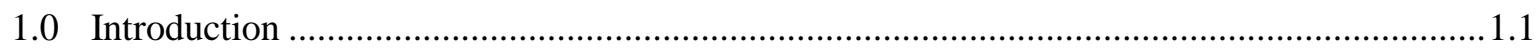

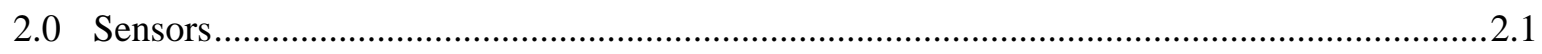

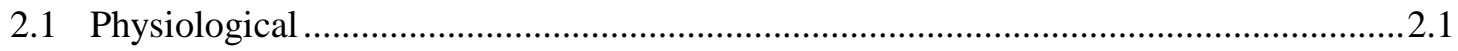

2.1.1 270 Vision Ltd.: BPM Physio ..................................................................... 2.1

2.1.2 Cambridge Consultants: Xelflex ................................................................... 2.1

2.1.3 Center for Sustainable Health: Project HoneyBee ............................................2.2

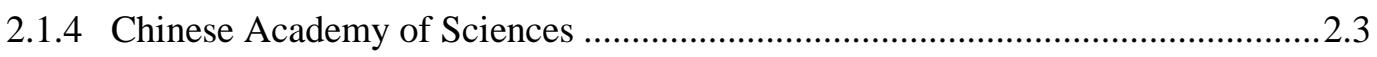

2.1.5 Florida International University in Miami and North Carolina State University. 2.3

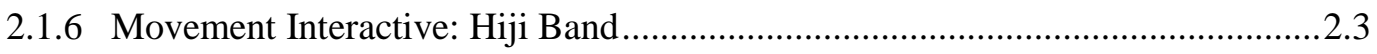

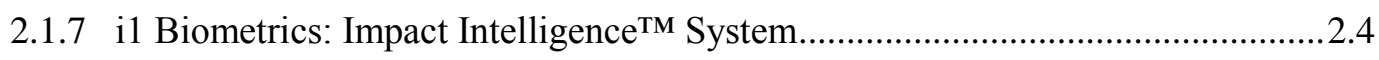

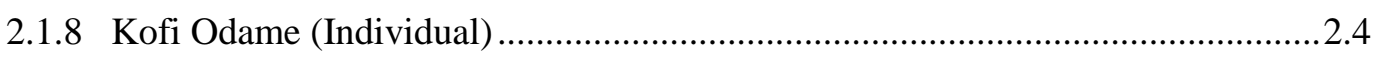

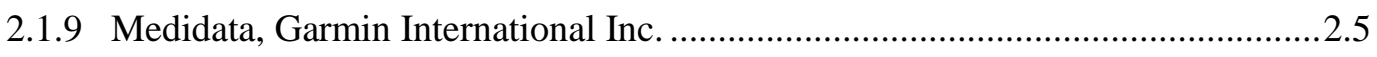

2.1.10 Scripps Translational Science Institute: Sensor Technology and Analytics to

Monitor, Predict and Protect Ebola Patients (STAMP2) .....................................2.6

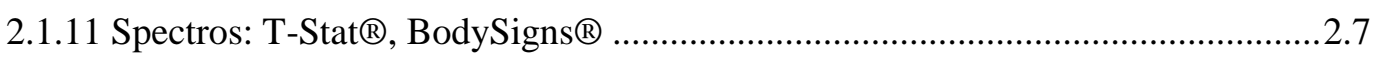

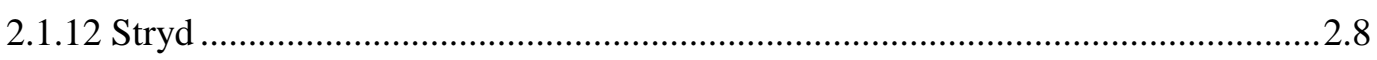

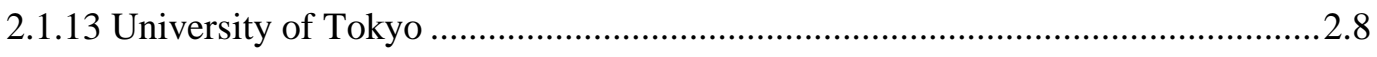

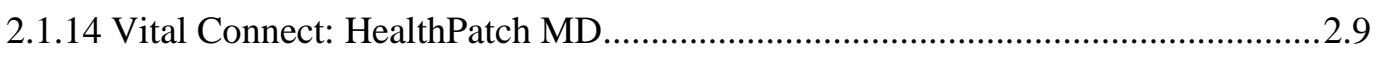

2.1.15 X2 Biosystems: Integrated Concussion Evaluation .........................................2.9

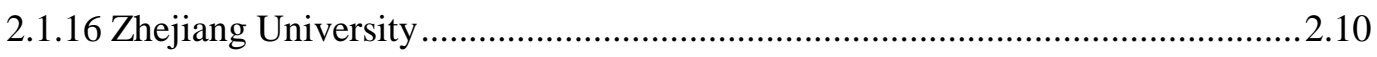

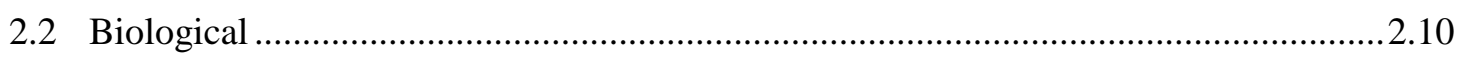

2.2.1 Edgewood Chemical Biological Center: VOCkit System .................................2.10

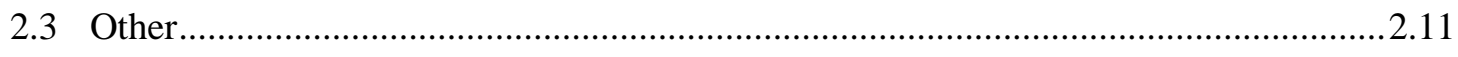

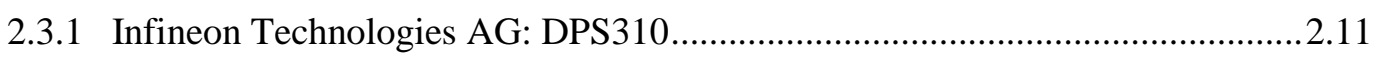

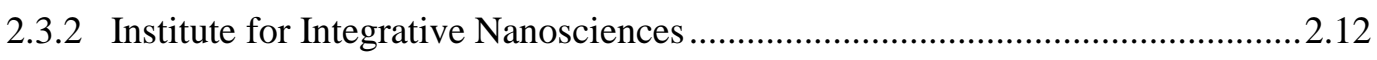

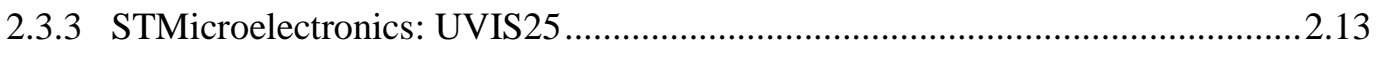

2.3.4 Universidad Politécnica de Madrid Institute of Optoelectronics Systems and

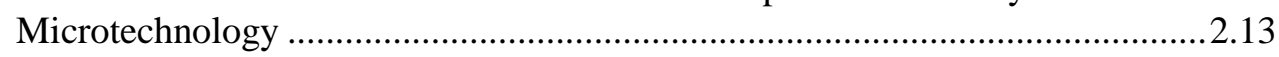

2.3.5 Yonsei University and Stanford University …...........................................2.14

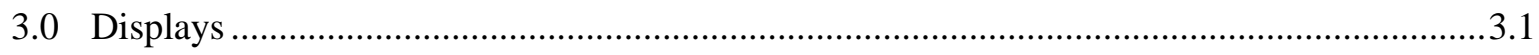

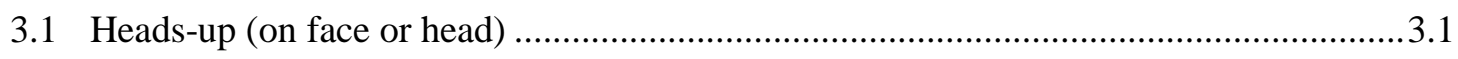

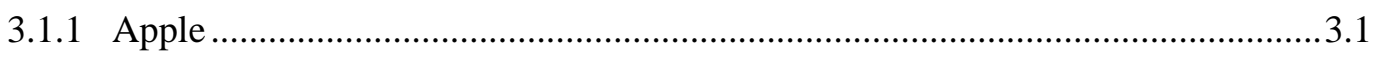

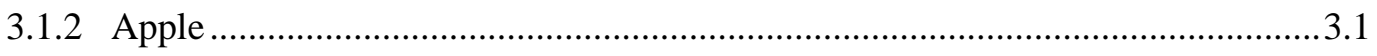

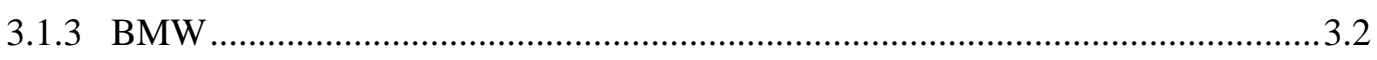

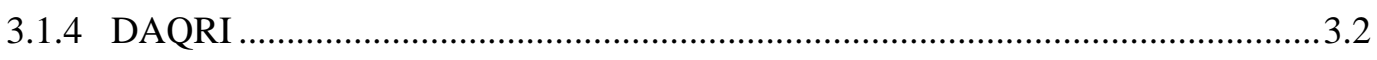

3.1.5 Google, Amsterdam's Schiphol: Google Glass..................................................3.3

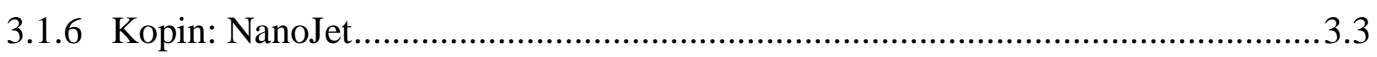


3.1.7 University Bremen, Friedrich Wilhelm Bessel Institute ..................................... 3.4

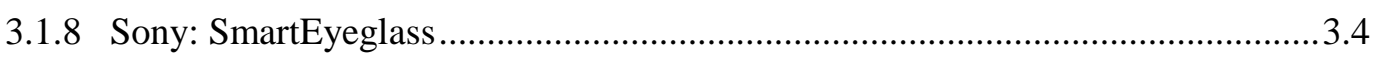

3.1.9 VitalMedicals: VitalVideo, VitalCom, VitalStream …......................................... 3.5

3.1.10 Vuzix, HeadApp: Glass4Flight .................................................................... 3.5

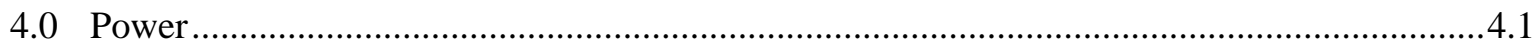

4.1 Self-powering (Harvesters) …............................................................................ 4.1

4.1.1 Chinese Academy of Sciences ..................................................................... 4.1

4.1.2 HSG-IMIT Institute of Micromachining and Information Technology ................4.1

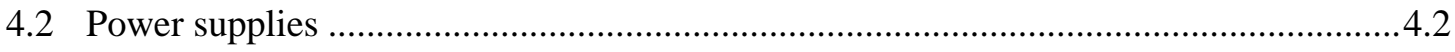

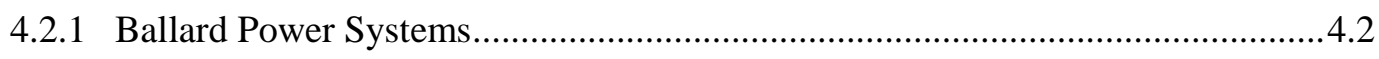

4.2.2 Sungkyunkwan University ...................................................................... 4.3

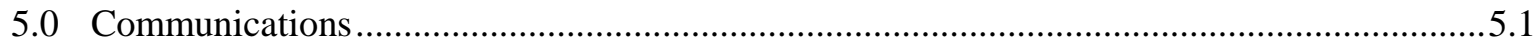

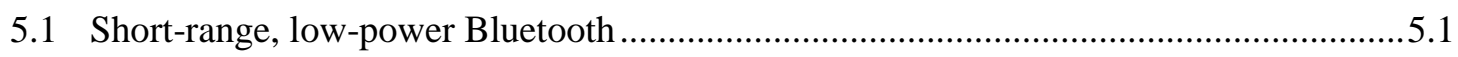

5.1.1 Automated Assembly Corporation: InfoSkin ................................................ 5.1

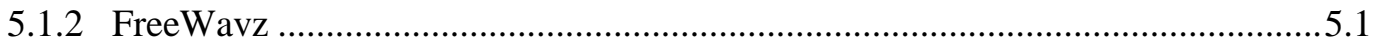

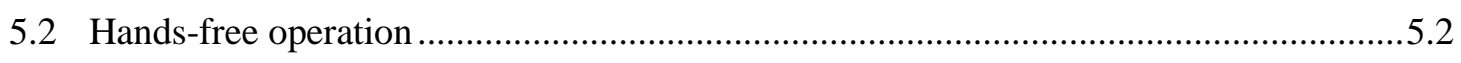

5.2.1 RHL Vision Technologies Pvt. Ltd.: Fin .......................................................5.2

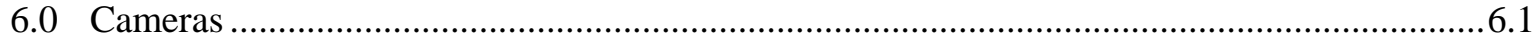

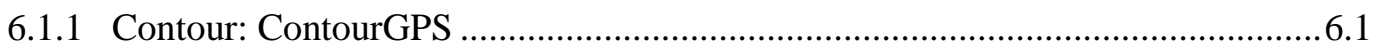

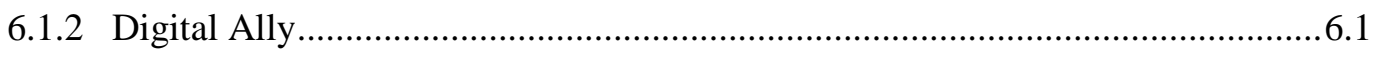

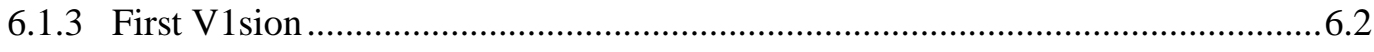

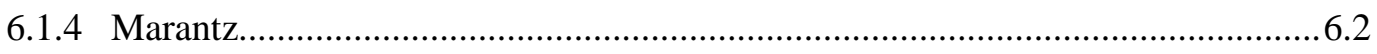

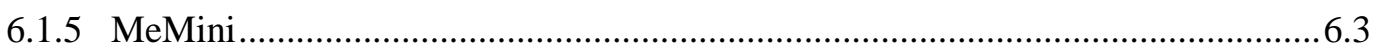

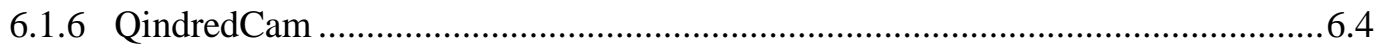

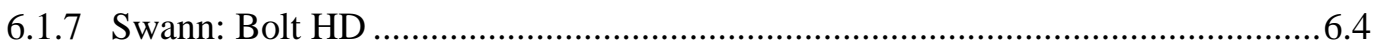

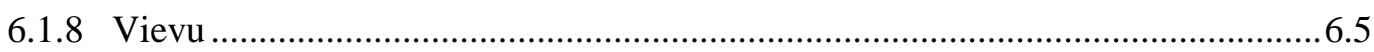

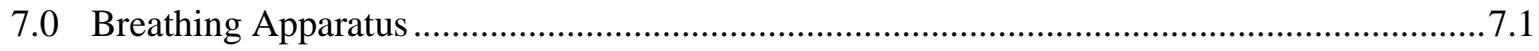

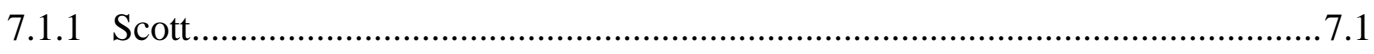

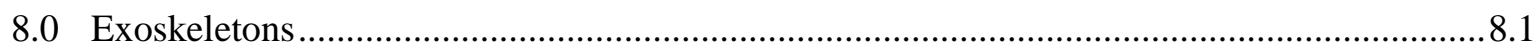

8.1.1 Hiroshima University: Sensorimotor Enhancing Suit ...................................... 8.1

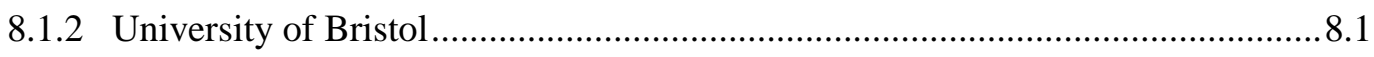

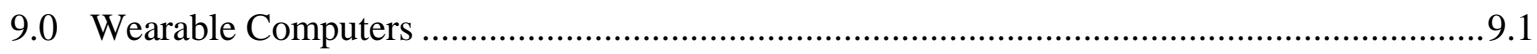

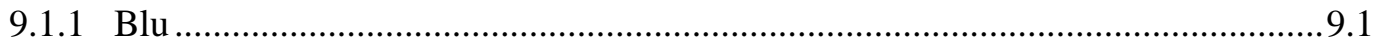

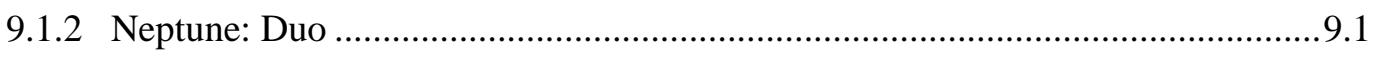

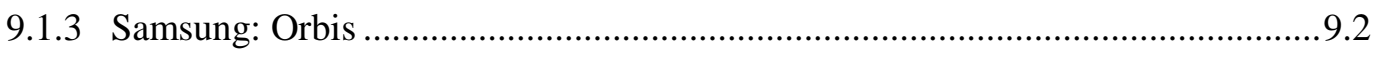

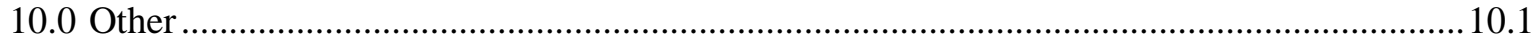

10.1.1 Avon Protection, SecureBio, Ltd. ............................................................ 10.1

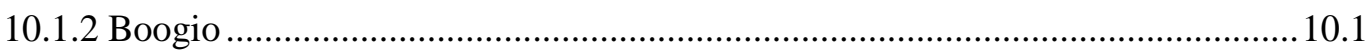

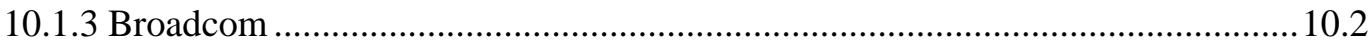




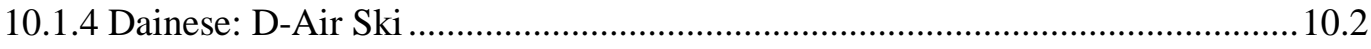

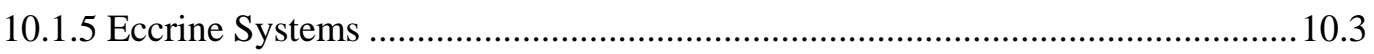

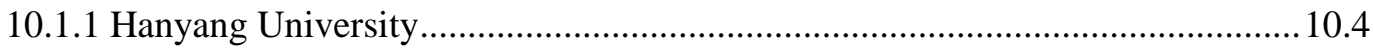

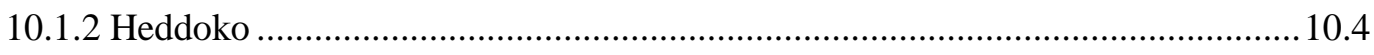

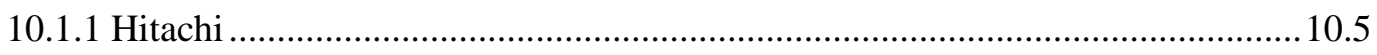

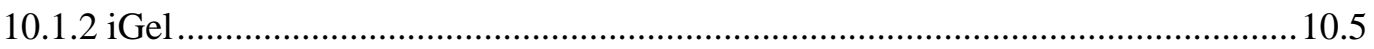

10.1.3 Immersion Corporation: Instinctive Alerts Framework ….................................. 10.6

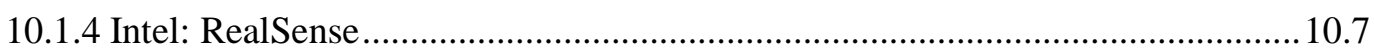

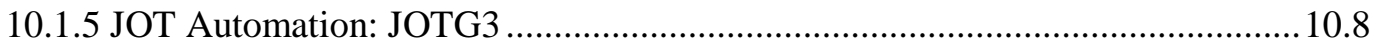

10.1.6 Kelvin Thermal Technologies, University of Colorado ..................................... 10.8

10.1.7 Massachusetts Institute of Technology: Sartorial Robotics ................................ 10.9

10.1.8 McLaren Applied Technologies ..................................................................... 10.9

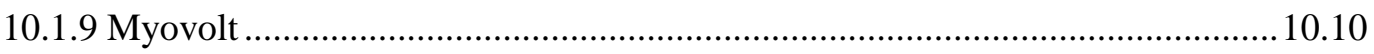

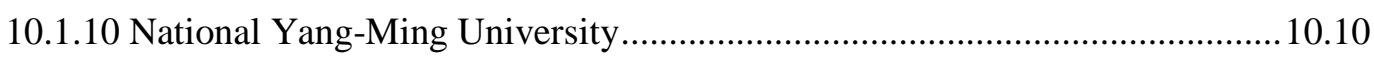

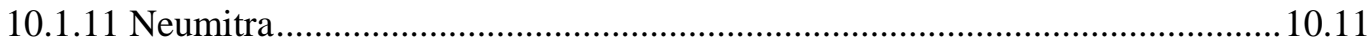

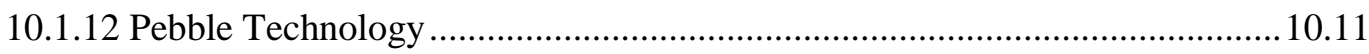

10.1.13Shepherd Pathways: EyeRemember.......................................................... 10.11

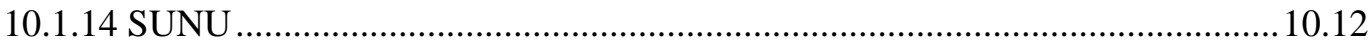

10.1.15Terje Norderhaug (individual): Airport AI ...............................................10.13

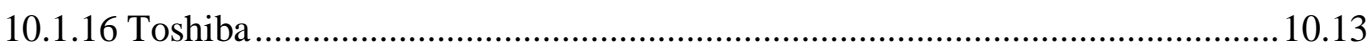

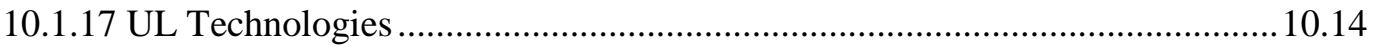

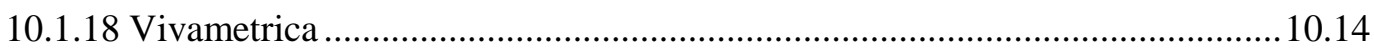

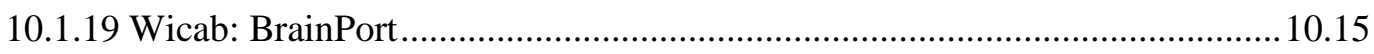

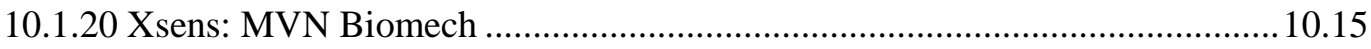

Appendix A Technology Summary ….............................................................................. 



\subsection{Introduction}

The Pacific Northwest National Laboratory (PNNL) is supporting the Department of Homeland Security (DHS) to advance technologies to enhance responder health and address complex and changing threat environments. The DHS Science and Technologies First Responders Group established the Responder Technology Alliance (RTA) to accelerate the development of solutions to first responder needs and requirements by identifying, analyzing, and recommending solutions that improve responder safety, enhance their ability to save lives, and minimize property loss. The end goal is for RTA to develop and implement strategies that will make effective solutions available to first responders.

As part of technology foraging for the RTA, this report summarizes technologies that are relevant in the area of "wearables," with the potential for use by first responders. The content was collected over the previous month(s) and reproduced from a general Internet search using the term wearables. Additional information is available at the websites provided. The content is organized by technology function including:

- Sensors - Devices that detect physiological, particle, and chemical activity

- Displays - Heads-up and body-worn visual displays

- $\quad$ Power - Wearable power systems including chargers, batteries, self-powering or harvesting technologies, and power supplies

- Integrated Communications - Voice and data communications systems utilizing Bluetooth, wireless, hands-free, ergonomically optimized systems, noise-filtering digital speakers or microphones, etc.

- Cameras - Body-worn photo and video cameras

- Breathing Apparatus - Wearable air supply and monitoring devices

- Exoskeletons - Whole or partial body suit that enhances mobility and physical performance

- Wearable Computers - Body-worn data processing devices

- General - Miscellaneous technologies as well as emerging trends or recent advances in the field of wearables.

This report is not meant to be an exhaustive list nor an endorsement of any technology described herein. Rather, it is meant to provide useful information about current developments in the area of wearable technology.

A spreadsheet summarizing these technologies is available in Appendix A. For an electronic copy, contact Jaki Upton at jaki.upton@pnnl.gov. 



\subsection{Sensors}

\subsection{Physiological}

\subsubsection{Vision Ltd.: BPM Physio}

Technology name: BPM Physio fitness tracker

Description: BPM Physio is a body-worn device that "uses the numerous sensors embedded inside it to collect a wide range of data that gets analyzed by the software. Once the analysis is done, the software uses the collected data to create a visual representation that allows for easy comparison between present and past data." The device connects to devices wirelessly using Bluetooth. It comprises movement sensors including an accelerometer, barometer, gyroscope, magnetometer, pedometer, and pressure sensors. It also features a rechargeable battery. An advantage to the device compared to others is that "Once your data has been collected, it is analyzed. The software is then responsible for the visual display of the relevant data. According to the product website, the device can "provide a clinician with live, animated feedback of the movement of the head/neck, upper extremities (shoulder, forearm, elbow and wrist) and lower extremities (hip, knee, and ankle) eliminating the need for a goniometer and inclinometers."

Status: Available

\section{Funding:}

Product link: http://www.bpmpro.co.uk/

Source: The BPM Physio Wearable Tech http://www.wearabletechdigest.com/2015/02/the-bpm-physio-wearable-tech.html

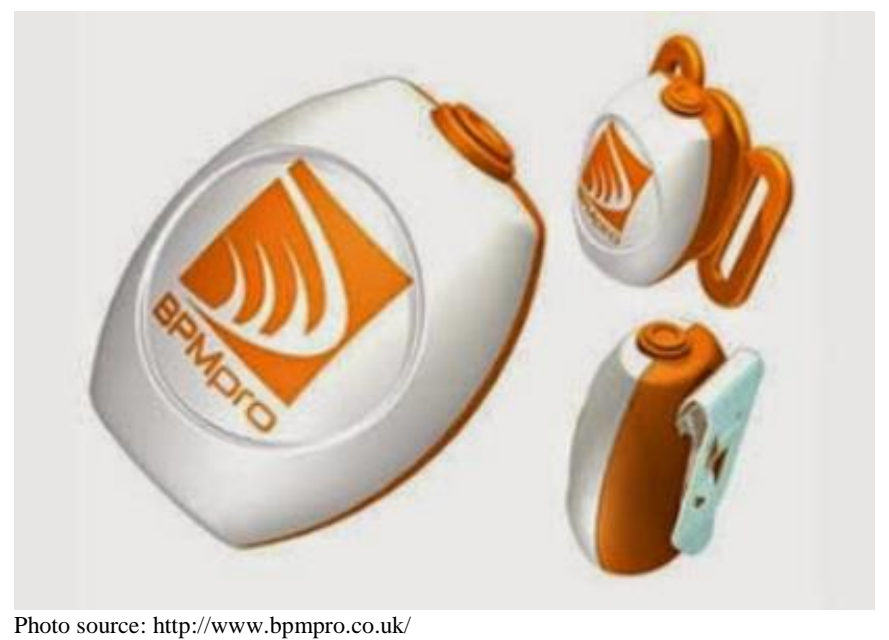

\subsubsection{Cambridge Consultants: Xelflex}

Technology name: Xelflex smart garment 
Description: XelfleX employs fiber-optic sensors and low-cost impulse radar in a garment. The device is highly flexible, waterproof (and expected to be washable) and "up to 10 sensors are possible along each fiber - with the initial light pulse sent by an LED in the electronics pack. Algorithms then turn the results from the sensors into guidance that users can easily understand, giving feedback on their posture and movement, and coaching them on how to improve." Reportedly a "single sensing fiber can cross up to about 10 joint regions and measure body position/motion at each of these locations simultaneously." The device is made up of "a credit-card sized electronics module powered by a rechargeable battery, giving around 24 hours of continuous use. The module is linked via Bluetooth to an app on a smartphone or smartwatch which gives real-time feedback to users." The device uses "low-cost, low-power ARM Cortex M0 processor coupled to intelligent yet low-cost RF analogue circuitry which takes care of all of the fast signal processing." The sensing garment capability is intended to benefit physiotherapy and rehabilitation markets.

Status: Evolving

\section{Funding:}

Product link: http://www.cambridgeconsultants.com/media/press-releases/innovation-wearable-tech

Source: Cambridge Consultants debuts 'unnoticeable' wearable tech http://eandt.theiet.org/news/2015/feb/xelfelx-cambridge.cfm

\subsubsection{Center for Sustainable Health: Project HoneyBee}

Technology name: Project HoneyBee

Description: The Center for Sustainable Health's (CSH) Project HoneyBee is a model for collecting and validating data to sustain human health. Project HoneyBee was designed to "harness the promise of wearable biosensors to revolutionize our ability to detect, diagnose, and prevent disease." The project responds to the need to "validate consumer-facing, inexpensive technologies within clinical settings to ensure that the data collected is truly useful." The project combines CSH's experience in validating biomarkers for clinical application with physiological metrics from wearable biosensors to address clinical problems. The creators propose that wearable biosensors will "help older adults better understand the chronic illnesses that are an inevitable part of growing older, while giving health providers the metrics to better manage disease at lower cost." CSH is currently performing observational clinical trials to test the utility of commercial wearable devices for monitoring patients.

Status: Evolving

\section{Funding:}

Product link: http://sustainablehealth.org/honeybee/

Source: Bringing the "Flip" home: Project HoneyBee's validation of wearable biosensors at the forefront of the next Flip the Clinic Lab

http://www.sustainablehealth.org/blog/bringing-flip-home-project-honeybees-validation-wearable-

biosensors-forefront-next-flip-clinic-lab/ 


\subsubsection{Chinese Academy of Sciences}

Technology name: Wearable temperature sensor using graphene nanowalls

Description: This research demonstrates "an ultrasensitive wearable temperature sensor innovated by an emerging material graphene nanowalls and its ease of combination with polydimethylsiloxane." The result is facile, biocompatible, and cost effective, with a positive temperature coefficient "three orders higher than that of conventional counterparts." According to researchers, "the sensor is capable of monitoring body temperature in real time, and presents quite fast response/recovery speed as well as longterm stability. Such wearable temperature sensor could constitute a significant step towards integration with the next frontier in personalized healthcare and human-machine interface system."

Status: Evolving

Funding:

Product link:

Source: Wearable Temperature Sensor Based on Graphene Nanowalls

http://pubs.rsc.org/en/content/articlepdf/2015/ra/c5ra00871a

\subsubsection{Florida International University in Miami and North Carolina State University}

Technology name: Wearable cortisol monitoring strip

Description: Scientists are developing a tiny wearable sensor strip to measure the hormone cortisol, which signals stress, as well as to track sleep and alert doctors when a person is dangerously tense. The device is anticipated to have benefits for people in high-stress jobs like first responders. Compared to previous methods for measuring cortisol, the strip would record levels over time. Researchers are also "in the process of starting human trials on flexible, wearable patches to see if they can successfully wick sweat from the body and measure various ions, hoping to predict muscle damage in athletes, among other things." Stress as a biomarker can be used to determine a number of things such as glucose levels in diabetics.

Status: Evolving

Funding:

Product link:

Source: Future of Measuring Stress - and Other Things — Is in Wearable Devices http://www.notimpossiblenow.com/lives/future-of-measuring-stress--and-other-things--is-in-wearabledevices

\subsubsection{Movement Interactive: Hiji Band}

Technology name: Hiji Band 
Description: The Hiji Band detects and reports traumatic brain injury in sports players or other users. Activity related to brain injury is reported to a mobile app. Sensors in the adjustable headband detect any impact. The sensors and computer software "automatically gathers and saves the impact data and sends alerts in real-time to those who use the integrated mobile app. The information is sent when a player wearing the band suffers any head collision. Important factors from the collision, such as speed, location and direction are tracked with the sensors." Additionally, the device gathers and interprets data long-term: "With the data, teams will be able to create a long-term record of all prominent head impacts that the player has faced. Easily comprehensible text, graphs, and images are used by the software to send the data to the users." The device also delivers audio and visual alerts to the user.

Status: Evolving

Funding: Crowdfunding - surpassed the pledge goal.

Product link: http://hijiband.com/

Source: Hiji Band- Wearable for Effective Concussion Detection http://www.augmentedrealitytrends.com/wearable-technology/hiji-band.html

\subsection{7 i1 Biometrics: Impact Intelligence ${ }^{\mathrm{TM}}$ System}

Technology name: Impact Intelligence System

Description: The Impact Intelligence System comprises the Vector Mouthguard with ESPTM Chip Technology to gather and analyze intracranial impact data and provide real-time objective information, such as "the location and level of each hit an athlete absorbed, and we can create a real-time assessment of the athlete's exposure to impacts sustained in the field." The system offers "a proprietary collection of advanced accelerometer and gyroscope technology embedded on a microscopic circuit board" as well as impact-sensing mouthguards, sideline assessment application, real-time wireless base station, customizable software package, mobile notification device, mouthguard charging stations, and a field kit case. The device can provide "quantitative and accurate real-time impact information, athlete information can be stored and monitored over entire athletic career, impact alerts wirelessly sent to sideline personnel, and a suite of tools supporting athlete assessment in bench vs. play decisions, recovery and safe return-toplay protocols."

Status: Evolving

\section{Funding:}

Product link: http://www.i1biometrics.com/product/

Source: i1 Biometrics Intelligence. The ground-breaking tool to understanding impacts in Sports. http://www.i1biometrics.com/product/

\subsubsection{Kofi Odame (Individual)}

Technology name: Wearable asthma-monitoring device

Description: Researcher Kofi Odame is developing a wearable asthma-monitoring device that sticks to a patient's chest, records their breathing sounds to "detect if a patient begins wheezing, and will send 
notifications to their smartphone if they need to make changes to their self-management plan or take medication." The device is designed to be low-energy consuming, "powered by the vibrational energy of the patient's natural motion and will remain on standby most of the time to conserve power, only waking up if it detects an abnormality. The device will be preloaded with a generic data set that will determine when a patient needs a notification, but it has the capacity to learn about the patient's own specific sound over time." These devices are intended to help medical professionals analyze large amounts of data to better understand and recognize medical conditions. Odame is also working on "a wearable cardiacmonitoring device that injects tiny amounts of current into a patient's chest and measures the resulting voltages, then reads the resulting impedance to create a virtual map of the heart. This device would be able to collect information more easily and to analyze a wider array of cardiac measurements."

Status: Evolving

\section{Funding:}

\section{Product link:}

Source: Odame: Wearable Biomedical Devices to Improve Treatment of Chronic Disease http://dujs.dartmouth.edu/biological sciences/odame-wearable-biomedical-devices-to-improve-treatmentof-chronic-disease\#.VO4iA00cRD8

\subsubsection{Medidata, Garmin International Inc.}

Technology name: Mobile health technology for clinical trials

Description: Medidata and Garmin are integrating Garmin's vívofit activity tracker with the Medidata Clinical Cloud $₫$ Medidata and the use of mobile health (mHealth) devices: "Designed to be worn on a person's wrist 24/7, Garmin's vívofit measures steps taken, distance, calories burned and hours slept. The water-resistant device - which displays fitness data through its always-on LCD display —is being used by Medidata to capture patient data in clinical trials. The company selected the vívofit because of the ease of use provided by its year-long battery life, which can improve the convenience and speed associated with capturing direct-from-patient data and, as such, has the potential to increase compliance among study participants in a clinical trial setting." The combined infrastructure "gathers data from devices worn by patients and integrates it with other traditional clinical data, including labs, vital signs, medical history and adverse events. In doing so, the infrastructure provides life sciences companies with the ability to conduct sophisticated analysis on trial performance. [ . . .] The data is pulled from the Garmin activity tracker in 15-minute increments and then analyzed to evaluate its connection with traditional clinical measures and determine whether it can provide better insight into patient health status or response to therapy. "

Status: Evolving

\section{Funding:}

Product link: $\underline{\text { https://www.mdsol.com/en }}$

Source: Medidata Teams Up with Garmin to Optimize Clinical Trials through Mobile Health Technology http://www.fiercecro.com/press-releases/medidata-teams-garmin-optimize-clinical-trials-through-mobilehealth-techno 


\subsubsection{Scripps Translational Science Institute: Sensor Technology and Analytics to Monitor, Predict and Protect Ebola Patients (STAMP2)}

Technology name: STAMP2: Sensor Technology and Analytics to Monitor, Predict and Protect Ebola Patients

Description: Scripps and partners Sotera Wireless, Rhythm Diagnostic Systems, and PhysIQ and developing a wireless device to screen for Ebola cases. STAMP2 "uses a mobile system and Band Aidtype sensor to pinpoint changes in individuals' condition, and continuously monitors patients' vital signs through two wireless monitors. [. . .] Data from the monitors is transmitted to PhysIQ's analytics platform, which uses next-generation algorithms to detect changes in patients over time. The platform provides automated analysis, offering information about an individual's condition before symptoms develop or worsen." Current plans include running the system "on a number of wireless health monitoring devices, including wireless rugged computers, smartphones and tablets with specially created apps. The completed program will also include a web portal that allows doctors to access a patient's status online." The device comprises "a disposable, Bluetooth-enabled sensor that goes on like a Band-Aid, and a hospital grade wireless vital sign sensor suite both of which will continuously measure key vital signs, including, heart rate, respiratory rate, temperature, and oxygen saturation of Ebola patients in ETUs and those suspected to be infected, allowing for remote monitoring, improved patient care and enhanced health care worker safety."

Status: Evolving

Funding: Grant from the U.S. Agency for International Development

Product link: http://www.scripps.org/news_items/5156-program-nominated-to-test-new-wirelessapproach-for-ebola-care

Source: USAID backs wearable tech initiative for Ebola from Scripps http://www.fiercemedicaldevices.com/story/usaid-backs-wearable-tech-initiative-ebola-scripps/2015-02$\underline{13}$

http://www.ebolagrandchallenge.net/wearable-patient-sensors 

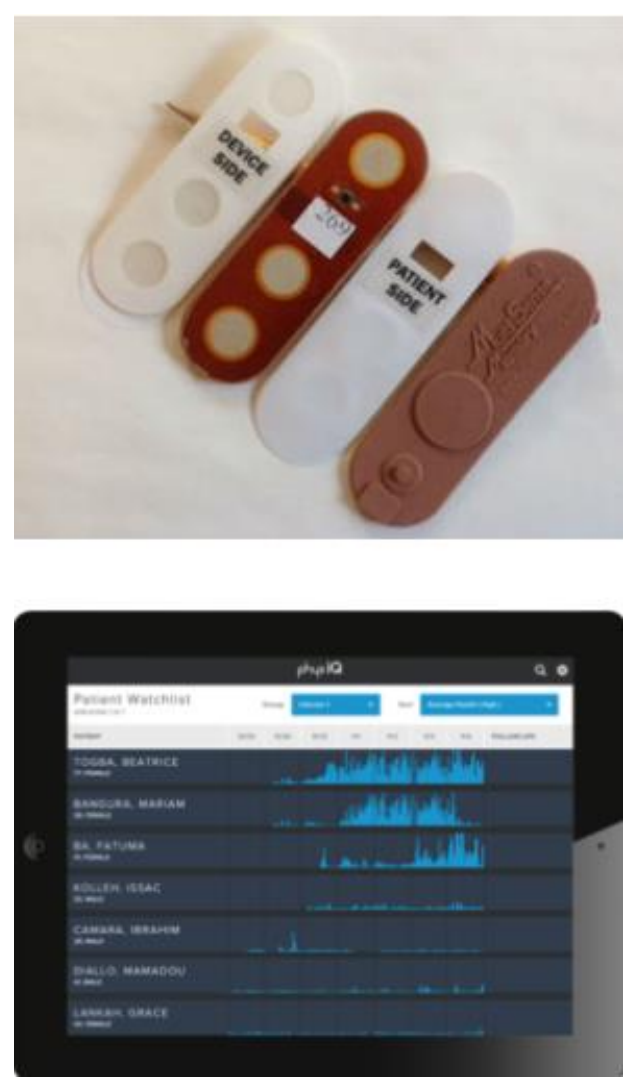

Photo Source: http://www.ebolagrandchallenge.net/wearable-patient-sensors

\subsubsection{Spectros: T-Stat ${ }^{\circledR}$, BodySigns $\AA$}

Technology name: T-Stat broadband tissue oximeter, BodySigns wearable fitness sensor

Description: The T-Stat tissue oximeter is "the first medical device FDA-approved as sensitive to ischemia, an insufficient supply of oxygen to tissue, and remains the only commercially-available tissue oximeter utilizing state-of-the-art multispectral technology. The non-invasive T-Stat VLS system is used clinically to provide a continuous and real-time absolute value, utilizing 260 wavelengths, over the competing NIRS oximeter product lines that only use 2-4." The BodySigns wearable fitness sensor is a "loose-fit heart rate monitor that uses white light to produce medical-grade data." The device features "sensor measures heart rate, respiratory rate, hydration, and even calories from a small, non-contact sensor" and is "suitable for incorporation into a wide array of low-power fitness and wearable consumer electronics products."

Status: Available

\section{Funding:}

Product link: http://www.spectros.com/products/t-stat-ischemia-detection/about-t-stat/systemoverview.html

Source: Spectros Corporation 2014 Oximeter Sales Revenue Up 42\% http://www.prnewswire.com/news-releases/spectros-corporation-2014-oximeter-sales-revenue-up-42$\underline{300030600 . \mathrm{html}}$ 


\subsubsection{Stryd}

Technology name: Stryd wearable power meter

Description: The small, wearable device uses first-of-its-kind sensing technology to calculate run power, measured in watts. Stryd links with most sports watches and mobile devices, and has a battery life of longer than a year. Stryd helps a user understand their performance and establish baseline data: Stryd "detects both the runner's force and velocity then uses this data to produce an instantaneous power reading. Force is measured from the impact forces created as the runner's foot hits the ground with each step. Velocity is measured using high-resolution motion sensors that calculate how the runner's body is moving through 3D space. Together, these two measurements are run through a complex algorithm, resulting in the runner's power."

Status: Evolving

Funding: Crowdfunding - more than doubled the goal of $\$ 50,000$

Product link: http://www.stryd.com/

Source: Stryd Launches First Wearable Power Meter For Runners http://triathlon.competitor.com/2015/02/gear-tech/stryd-launches-first-wearable-power-meter$\underline{\text { runners_112181 }}$

\subsubsection{University of Tokyo}

Technology name: Wearable fever alarmband

Description: This wearable, flexible, and self-powered fever alarmband sounds an alarm in the case of high body temperature. The device combines "flexible amorphous silicon solar panel, piezoelectric speaker, temperature sensor and power supply circuit created with organic components in a wearable package." The device is $30 \mathrm{~cm}$ long and $18 \mathrm{~cm}$ wide. Developers suggest the device "demonstrates that it is possible to produce flexible, disposable devices," which would benefit caregivers in a healthcare setting and potentially evolve to provide "audible feedback on body temperature, or combined with other sensors to register wetness, pressure or heart rate."

Status: Evolving

\section{Funding:}

\section{Product link:}

Source: Printable wearable fever alarm includes 'several firsts' http://www.newelectronics.co.uk/electronics-news/printable-wearable-fever-alarm-includes-several$\underline{\text { firsts/74058/ }}$ 


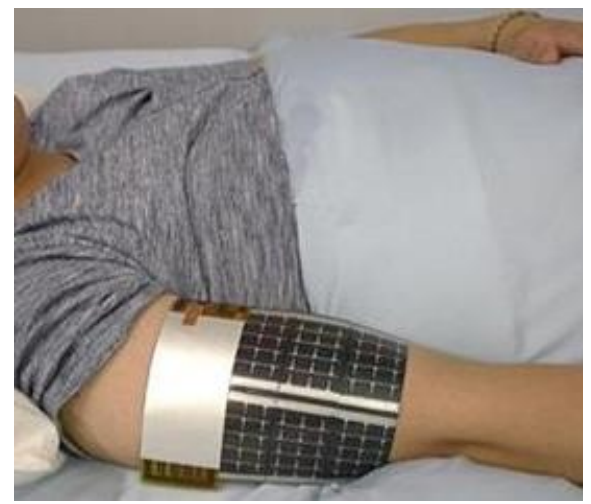

Photo source: http://www.t.u-tokyo.ac.jp/etpage/release/2015/150226_2.html

\subsubsection{Vital Connect: HealthPatch MD}

Technology name: HealthPatch MD

Description: HealthPatch MD is "a small, thin wearable device that can monitor a number of biometric signals, providing medical professionals with the ability to remotely monitor patients' respiratory and cardiac data, body movement, temperature, and other such health indicators. The data is transferred via BlueTooth 4.0 and can be interpreted and analyzed using Vital Connect's custom-designed software." The device is water resistant, has a 48-72 hour battery life, and is fully disposable. The chest-worn device features ECG electrodes to detect heart rate, an accelerometer to detect motion, and thermistor to detect skin temperature. The device was approved for the Japanese market, FDA clearance for sale in the US, regulatory approval (CE Mark) for distribution in EU, and it is registered for distribution in Canada.

Status: Evolving

Funding:

Product link: http://www.vitalconnect.com/healthpatch-md

Source: HealthPatch MD Wins Approval for Japanese Market

http://mobileidworld.com/healthpatch-md-wins-approval-for-japanese-market-2131/

\subsubsection{X2 Biosystems: Integrated Concussion Evaluation}

Technology name: Integrated Concussion Evaluation (ICE)

Description: The Integrated Concussion Evaluation is a cloud-based application that combines wearable biometric sensors and mobile software to spot, monitor, and enable response to traumatic brain injury. The device is currently in use by more than 30 national hockey teams and anticipated to have applications for first responders, where "Traumatic brain injury is also a problem plaguing law enforcement and military personnel who are exposed to concussive blasts among other types of head-related violence. Wearable tech and biometrics are being applied more frequently in order to understand a person's exposure to brain injury so that the proper measures can be taken." According to the developer's web site, the device draws from SCAT 2/SCAT 3/NFL derived protocol, cloud-based access, real-time field data, multi-factor exams, concussion history and risk factors, return-to-play management tools, and iPad compatibility. The device "provides real time, multi-factor baseline comparison for rapid highlighting of post-injury deficiencies that help to verify or dismiss a suspected concussion. The brain health of athletes 
is tracked throughout their entire careers by the X2 ICE as they progress through levels of competition and engage in different activities. X2 ICE helps athletic organizations to build long term profiles of concussion assessment, recovery and return-to-play."

Status: Evolving

Funding:

Product link: http://www.x2biosystems.com/x2_ice/

Source: NHL Chooses Wearable Biometrics To Detect Brain Trauma

http://mobileidworld.com/nhl-chooses-wearable-biometrics-to-detect-brain-trauma-2032/

\subsubsection{Zhejiang University}

Technology name: Wearable sensor systems for infants

Description: Researchers are addressing wearable sensor systems and frameworks for infants. This research explores the "development of and fusion of wearable sensing technologies, wireless communication techniques and a low energy-consumption microprocessor with high performance data processing algorithms" for the continuous health status monitoring of infants. According to the article, "As a clinical tool applied in the constant monitoring of physiological parameters of infants, wearable sensor systems for infants are able to transmit the information obtained inside an infant's body to clinicians or parents. Moreover, such systems with integrated sensors can perceive external threats such as falling or drowning and warn parents immediately."

Status: Evolving

Funding: Supported in part by the NSFC Grant No. 61428304 and the China State Key Laboratory of Robotics and System (HIT) SKLRS-2014-ZD-04.

\section{Product link:}

Source: Wearable Sensor Systems for Infants http://www.mdpi.com/1424-8220/15/2/3721

\subsection{Biological}

\subsubsection{Edgewood Chemical Biological Center: VOCkit System}

\section{Technology name: VOCkit system}

Description: The VOCkit system was adapted from commercial technology to detect and differentiate chemical and biological hazards and transmit results to the higher command. The device "uses a postage stamp-sized colorimetric detection assay printed with a grid of several dozen indicator chemicals with the ability to identify threats such as anthrax, sarin or mustard gas. The system can then transmit the results via soldiers' Nett Warrior smartphones." The device was 3D printed and "placed in inside a disk-like cartridge. A plug on the cartridge can be removed to add a sample for testing, after which the assay's grid of colored indicator chemicals reacts to reveal the sample's composition." According to the Army's press 
release, "At the heart of the system is a colorimetric detection assay, a swatch of paper about the size of a postage stamp, that is printed with a grid of several dozen indicator chemicals arranged in a grid of small dots. Each dot is made from a differently-colored indicator chemical that will have a unique color change in response to any compound it comes in contact with: from chemical threats, to biological threats, to common household cleaning products and cosmetics."

Status: Evolving

\section{Funding:}

Product link:

http://www.army.mil/article/143059/New_devices_may_soon_help_Soldiers_nose_out_chemicals_bio_t hreats/

Source: Handheld devices improve bio and chemical threat detection http://defensesystems.com/articles/2015/02/20/army-handheld-biological-chemicaldetection.aspx?admgarea $=\mathrm{DS}$

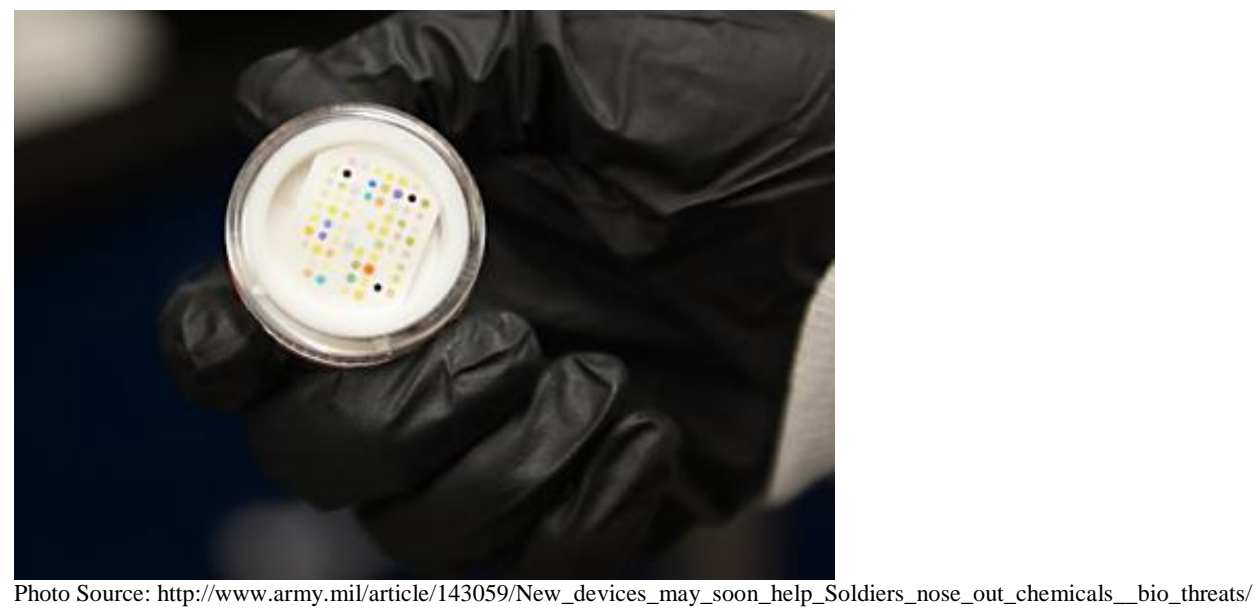

\subsection{Other}

\subsubsection{Infineon Technologies AG: DPS310}

Technology name: DPS310 Micro Electro Mechanical System (MEMS)

Description: DPS310 is a miniature barometric air pressure and temperature sensor. The low-power device, measuring $2.0 \mathrm{~mm} \times 2.5 \mathrm{~mm} \times 1.0 \mathrm{~mm}$, features an "ultra-high $\pm 5 \mathrm{~cm}$ resolution, miniature MEMS (Micro Electro Mechanical Systems) pressure sensor" that supports "the development of new and enhanced navigation, location, well-being, gesture recognition and weather monitoring applications." The device provides accuracy, even at pressures from $300 \mathrm{hPa}$ to $1200 \mathrm{hPa}$ and at temperatures from $-40^{\circ} \mathrm{C}$ to $85^{\circ} \mathrm{C}$. The device is anticipated to be "ideal for indoor navigation and assisted location applications such as floor detection in shopping malls and parking garages- and outdoor navigation where it can help to improve navigation accuracy or support 'dead reckoning' when GPS signal is not available." The device's accuracy and resolution could help "in identifying when a person is moving from one floor of a building to another and triggering the download of a new floorplan. High-accuracy height measurement is 
also required by sports and fitness applications that need to differentiate between the different types of 'steps' a wearer might be taking and the corresponding calorie 'burn rate'."'

Status: Soon to be released

\section{Funding:}

Product link: http://www.infineon.com/dgdl/Infineon-

PB_DPS310_Digital_Barometric_Pressure_Sensor-PB-v01_00-

EN.pdf?fileId $=5546 \mathrm{~d} 4624 \mathrm{bbf60fb014bc100f8150839}$

Source: Low-power barometric pressure sensor for mobile and wearable gadgets and IoT devices http://phys.org/news/2015-02-low-power-barometric-pressure-sensor-mobile.html

\subsubsection{Institute for Integrative Nanosciences}

Technology name: Magnetic field sensor

Description: Researchers are developing a sensor that would allow users to detect magnetic fields. It is essentially "an electronic skin with a magneto-sensory system that equips the recipient with a 'sixth sense' able to perceive the presence of static or dynamic magnetic fields." The ultrathin magnetic sensors are less than 2 micrometers thick and weigh 3 grams per square meter, and they withstand stretching, bending, and crumpling without sacrificing sensor performance. Researchers suggest the technology could lead to "wearable as imperceptible magneto-sensitive skin that enables proximity detection, navigation and touchless control."

Status: Evolving

Funding: Funded in part by the Nanett project of the German Federal Ministry of Education and Research (BMBF) and European Research Council under the European Union's Seventh Framework Program (FP7/2007-2013)/ERC grant agreement number 306277. The work in Tokyo was supported by the JST Someya Bio-Harmonized ERATO grant.

Research link: http://www.nature.com/ncomms/2015/150121/ncomms7080/full/ncomms7080.html

Source: The sensor that can give you a SIXTH SENSE: Film can give hands the ability to 'feel' magnetic fields

http://www.dailymail.co.uk/sciencetech/article-2938706/The-sensor-SIXTH-SENSE-Film-hands-abilitysense-magnetic-fields.html 


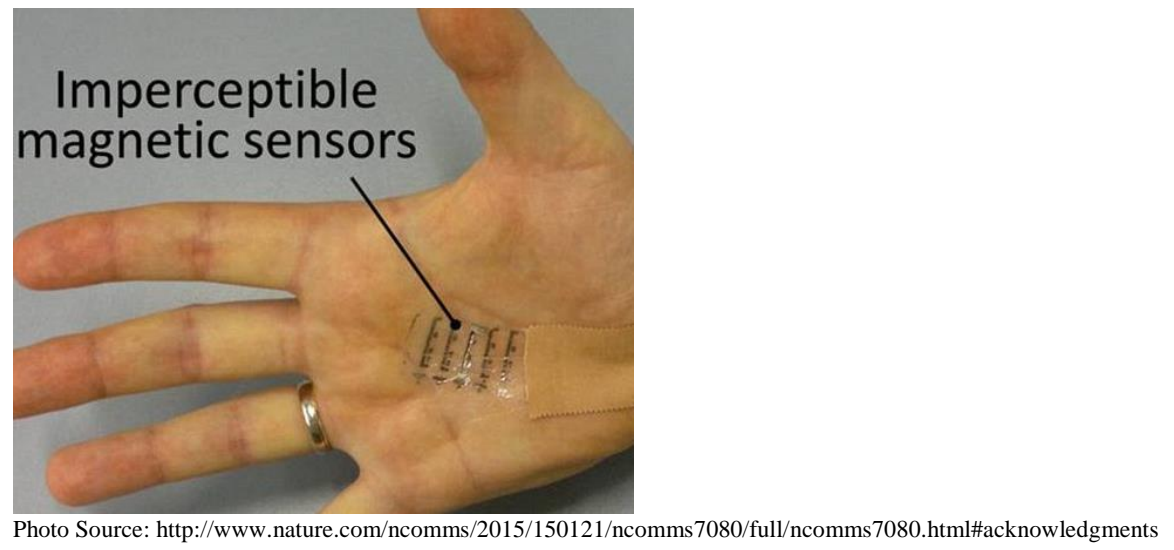

\subsubsection{STMicroelectronics: UVIS25}

Technology name: UVIS25 ultraviolet radiation sensor

Description: The UVIS25 ultraviolet sensor device comprises "a digital ultra-compact UV sensor aimed at all UV-sensing markets, including wearable devices, smartphone and tablet apps, and weather-station equipment. Leveraging patented ST technology, the device is sensitive to UV waves in the 200-400nm range, encompassing the key UV-A (315-400nm) and UV-B (280-315nm) wavelengths that are of greatest concern to human-health effects. Delivering more than just sensing, the UVIS25 calculates the UVI internally, uniquely eliminating the need for external processing algorithms or calibration on the customer's manufacturing line." The key features of the device include "a UVI output range of 0-15 with a resolution of just 1/16, SPI and I2C interfaces, 1.7 to $3.6 \mathrm{~V}$ supply voltage range, and the ability to provide updated UVI values as often as every second. The device is supplied in a $2.5 \times 2.5 \times 0.76 \mathrm{~mm}$ LGA10L transparent molded package."

Status: Soon to be released

\section{Funding:}

Product link:

http://www.st.com/web/en/catalog/sense_power/FM89/SC2014?icmp=sc2014_pron_pr_feb2015\&sc=uvi $\underline{\text { ndex-pr }}$

Source: Compact digi UV Sensor for mobile, wearable, and IoT apps http://www.eeherald.com/section/new-products/onws20150228004d.html

\subsubsection{Universidad Politécnica de Madrid Institute of Optoelectronics Systems and Microtechnology}

Technology name: Flexible nanosensors

Description: Researchers are developing "optical nanosensors capable of sticking on uneven surfaces and biological surfaces like human skin" and measure temperature, breadth, heart pressure, etc. The nanosensors use low-cost materials such as standard polycarbonate compact disks, aluminum films, and adhesive tapes. The flexible nanosensors are created by "manufacturing sensors over a compact disc of traditional polycarbonate, and secondly, transferring these sensors to adhesive Scotch tapes by a simple 
stick-and-peel procedure." According to researchers, "These flexible nanosensors enable us to measure refractive index variations of the surrounding medium and this can be used to detect chemical substances. Besides, they display iridescent colors that can vary according to the viewing and illumination angle, this property facilitates the detection of position variations and surface topography to where they are stuck at a glance."

Status: Evolving

Funding: Financial support from MINECO, Spain (TEC2012-31145).

Research link: http://dx.doi.org/doi:10.1039/C4NR06271J

Source: Flexible nanosensors for wearable devices http://www.nanowerk.com/nanotechnology-news/newsid=39171.php

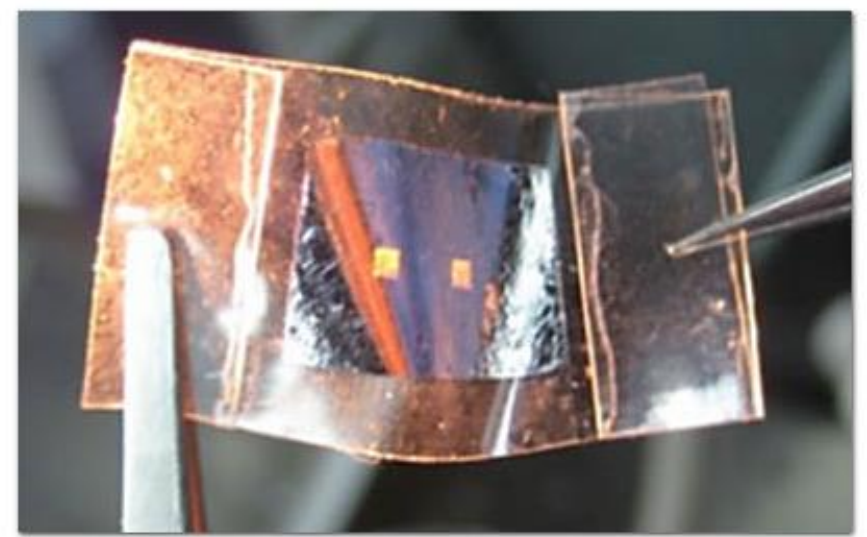

Aluminum film with two optical sensors over a Scotch adhesive tape. The sensor area is $1 \mathrm{~mm} \times 1$ mm. (Image: UPM)

Photo aource: http://dx.doi.org/doi:10.1039/C4NR06271J

\subsubsection{Yonsei University and Stanford University}

Technology name: Conductive Fiber-Based Ultrasensitive Textile Pressure Sensor

Description: Researchers are using highly conductive fibers coated with dielectric rubber materials to develop a flexible and sensitive textile-based pressure sensor. The sensor "exhibits superior sensitivity, very fast response time, and high stability compared with previous textile-based pressure sensors. By using a weaving method, the pressure sensor can be applied to make smart gloves and clothes which can control machines wirelessly as human-machine interfaces."

Status: Evolving

Funding: Supported by the Priority Research Centers Program (Grant Nos. 2009-0093823) through the National Research Foundation (NRF) of Korea funded by the Ministry of Education, Science and Technology (MEST) and Mid-career Researcher Program through NRF grant funded by the MEST (Grant No. 2014R1A2A2A09053061) This work was also supported by the Ministry of Higher Education, Kingdom of Saudi Arabia for supporting this research through a grant (PCSED-009-14) under the Promising Centre for Sensors and Electronic Devices (PCSED) at Najran University, Kingdom of Saudi 
Arabia and Basic Science Research Program through the NRF funded by the Ministry of Education, Science and Technology (Grant No. 2012R1A1A2042106).

\section{Product link:}

Source: Conductive Fiber-Based Ultrasensitive Textile Pressure Sensor for Wearable Electronics http://onlinelibrary.wiley.com/doi/10.1002/adma.201500009/abstract

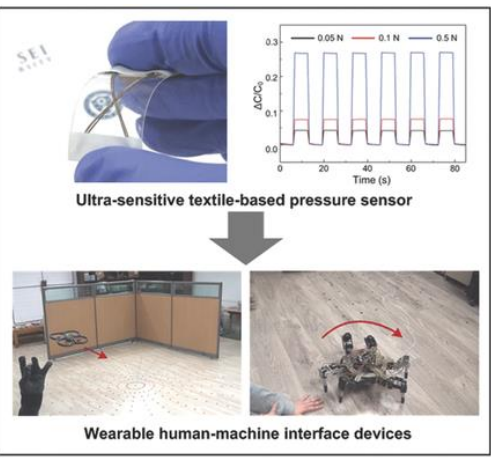

Photo source: http://onlinelibrary.wiley.com/store/10.1002/adma.201500009/asset/image_m/adma201500009-gra-0001m.png? $=1 \& \mathrm{~s}=18 \mathrm{ce} 715 \mathrm{cb} 8 \mathrm{~d} 8 \mathrm{a} 6781 \mathrm{f} 68 \mathrm{e} 95 \mathrm{dbc} 8 \mathrm{~d} 34 \mathrm{bbb} 9 \mathrm{f} 12 \mathrm{bc} 3$ 



\subsection{Displays}

\subsection{Heads-up (on face or head)}

\subsubsection{Apple}

Technology name: Head-Mounted Display Apparatus for Retaining a Portable Electronic Device with Display (Patent No. 8,957,835)

Description: Apple was granted intellectual property rights for a "Head-Mounted Display Apparatus for Retaining a Portable Electronic Device with Display" that features a slot for inserting an iPhone. Similar to the Samsung Gear VR, the proposed device uses the smartphone screen as the display and offers a hand-held remote control.

Status: Evolving

\section{Funding:}

Product link: http://patft.uspto.gov/netacgi/nphParser?Sect $1=$ PTO2\&Sect2=HITOFF $\& p=1 \& u=\% 2 F n e t a h t m 1 \% 2 F P T O \% 2 F s e a r c h-$ bool.html\&r=1\&f=G\&l=50\&co1=AND\&d=PTXT\&s1=8957835\&OS=8957835\&RS=8957835

Source: Did Apple Just Patent Samsung's Gear VR Headset? http://me.pcmag.com/wearable-tech/1007/news/did-apple-just-patent-samsungs-gear-vr-headset

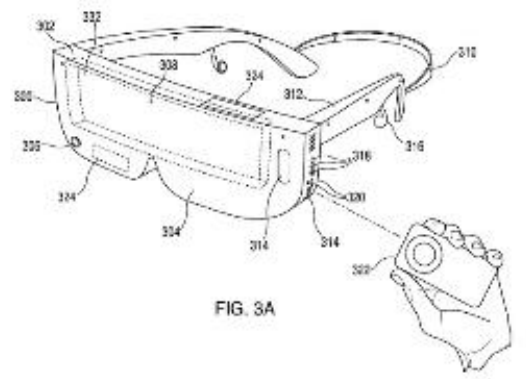

Photo Source: http://patft.uspto.gov/netacgi/nph-Parser?Sect1=PTO2\&Sect2=HITOFF\&p=1\&u=\%2Fnetahtml\%2FPTO\%2Fsearchbool.html\&r=1\&f=G\&l=50\&co1=AND\&d=PTXT\&s $1=8957835 \& O S=8957835 \& R S=8957835$

\subsubsection{Apple}

Technology name: Presentation device

Description: Apple was granted a patent for a device for "controlling operations of a portable presentation device to be worn by a user and that is capable of presenting media content to the user such as earphones, headphones, goggles or faceplates with video/audio capabilities." The device may feature a range of sensors including a "proximity sensor (e.g. an infra-red sensor, a laser sensor, a SONAR sensor, or any other type of sensor that can sense distance/proximity), a temperature sensor, and a pressure sensor." 
Status: Evolving

\section{Funding:}

Product link: http://patft.uspto.gov/netacgi/nphParser?Sect $1=$ PTO2\&Sect2=HITOFF $\& \mathrm{p}=1 \& \mathrm{u}=\% 2$ Fnetahtml\%2FPTO $\% 2$ Fsearch bool.html\&r=1\&f=G\&l=50\&co1=AND\&d=PTXT\&s1=8,954,177\&OS=8,954,177\&RS=8,954,177

Source: Apple Granted Patent for a Wearable Presentation Device http://www.patentlyapple.com/patently-apple/2015/02/apple-granted-patent-for-a-wearable-presentationdevice.html

\subsubsection{BMW}

Technology name: Virtual reality goggles

Description: BWM's virtual reality goggles "will work similarly to the Google Glass in sharing information on a lens to improve safety and driving experiences. Speed data will be collected, and car sharing and travel update alerts will be projected onto the screen." The goggles are supposed to help drivers park and are "an extension of the self-parking technologies already installed in new BMW models. Connecting with collision detection sensors and cameras in the vehicle, the goggles will project the car's surroundings (like the pavement, pedestrians or oncoming traffic) onto the eyewear while the car's chassis 'disappears' as the driver looks over their shoulder, allowing them to parallel park with ease."

Status: Evolving

\section{Funding:}

Product link: http://www.bmw.com/com/en/owners/service/augmented_reality_introduction_1.html

Source: BMW developing high-tech goggles to help drivers park http://www.techworld.com/news/wearables/bmw-has-wearable-in-development-in-silicon-valley-plant3597254/

\subsubsection{DAQRI}

Technology name: Melon headband and DAQRI Smart Helmet

Description: DAQRI, augmented reality helmet developer, acquired Melon, developer of an electroencephalogram (EEG, detects electrical activity in the brain) tracking headband. Whereas Melon was originally designed to test a user's focus using an EEG, this partnership will advance the technology "to monitor the stress level, skin temperature, fatigue and heart rate of the users." DAQRI reportedly plans to incorporate Melon's headband into its Smart Helmet product. Smart Helmet is part of DAQRI's 4D work to develop technology that projects data on a user's environment. Developers propose that "EEG space has immediate potential to enhance 4D wearables with safety features, as well as long term potential to create a game-changing brain-computer interface that will allow you to control 4D interfaces and objects in the real world."

Status: Evolving 
Funding: Crowdfunding

\section{Product link:}

Source: DAQRI Acquired Wearable Technology Start-Up Melon http://www.augmentedrealitytrends.com/wearable-technology/daqri-acquires-melon.html

\subsubsection{Google, Amsterdam's Schiphol: Google Glass}

Technology name: Google Glass

Description: Google Glass is being tested at the Amsterdam's Schiphol's airport authority officers "as a hands-free way to look up gate and airplane information" and to test "Google's face computer on travelers passing through the terminal in a bid to better understand the 'customer journey', thanks to Glass' first person perspective." The trial has included developing an app that "lets staff ask the device for gate or aircraft data and have the results displayed via the headset or on their smartphone. Another future feature the airport hopes to implement is the ability to measure the placement distance of barriers on the taxiway just by looking at them, rather than officers having to manually take measurements. It goes without saying that that's going to require a very thin margin of error."

Status: Evolving

\section{Funding:}

Product link: https://www.google.com/glass/start/

Source: Google Glass Is Being Trialed At European Airport

http://techcrunch.com/2015/02/09/glass-schiphol/

\subsubsection{Kopin: NanoJet}

Technology name: NanoJet

Description: Kopin, a microdisplay supplier of headset and rugged solutions, is developing a "NanoJet process for its liquid crystal cell assembly. The NanoJet process releases tiny drops of liquid crystal material with greater precision (variation within a few nano grams) and provides for a purer, better controlled and very uniform layering of the liquid crystal material in the fabrication of displays, resulting in superior image quality and higher brightness." The technology is "optimized for microdisplays with tiny pixels required for augmented reality and virtual reality applications." The technology is anticipated to deliver improved display performance with superior image quality, higher display brightness, and increased high temperature operating range.

Status: Evolving

\section{Funding:}

Product link: http://www.kopin.com/ 
Source: Kopin Develops Innovative NanoJet Process for Micro LCDs to Serve Emerging AR and VR Markets

http://www.marketwatch.com/story/kopin-develops-innovative-nanojet-process-for-micro-lcds-to-serveemerging-ar-and-vr-markets-2015-02-05?reflink=MW news stmp

\subsubsection{University Bremen, Friedrich Wilhelm Bessel Institute}

Technology name: Hybrid brain-computer interface (BCI) headset

Description: The proposed headset integrates "a steady-state visual evoked potential (SSVEP)-BCI, an event-related (de)-synchronization (ERD/ERS)-BCI, an eye tracker, an environmental observation camera, and a new EEG head cap for wearing comfort and easy preparation." The hybrid BCI headset "enables research for a Human Machine Interface that is optimally adapted to requirements of the user and the tasks to be carried out." According to developers, the "sBCI concept may become useful for healthy people in cases where a 'hands-free' handling of devices is necessary." Although the BCI has been developed for disabled users, it may also have applications for first responders with a need for hands-free operations.

Status: Evolving

Funding: Arbeitsgemeinschaft industieller Forschungsvereinigungen provided the grant for research project (16136BG).

\section{Product link:}

Source: sBCI-Headset - Wearable and Modular Device for Hybrid Brain-Computer Interface http://www.mdpi.com/2072-666X/6/3/291

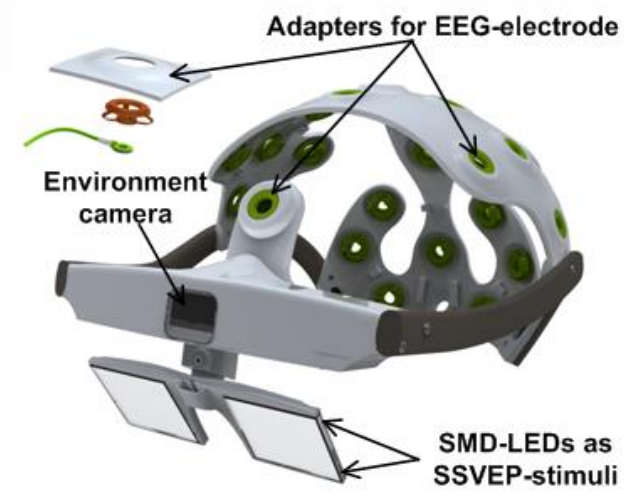

Photo Source: http://www.mdpi.com/2072-666X/6/3/291/htm

\subsubsection{Sony: SmartEyeglass}

Technology name: SmartEyeglass

Description: Sony's SmartEyeglass “internet-linked eyewear" superimposes information (text, symbols, images) onto the user's field of view. According to the article, "A version of the eyewear tailored for software developers will be available in Japan, Germany, Britain, and the United States on March 10." 
SmartEyeglass features an accelerometer, gyroscope, electronic compass, brightness sensor, microphones, Bluetooth, Android compatibility, 3M pixel camera, VGA movie capability.

Status: Soon to be released

\section{Funding:}

\section{Product link:}

Source: Sony steps up in wearable space with SmartEyeglass (Update)

http://articles.economictimes.indiatimes.com/2015-02-18/news/59269248_1_google-glass-eyewear-glassteam

\subsubsection{VitalMedicals: VitalVideo, VitalCom, VitalStream}

Technology name: VitalVideo, VitalCom, VitalStream smart glass technologies

Description: VitalMedicals offers three smart glass enabled products for use in medical settings:

"VitalVideo streams live ultrasound, fluoroscopy, and endoscopy video to smart glasses and tablets during procedures, bringing that data right into a surgeon's field of view. VitalCom enables clinicians to talk with anyone else in the hospital with just a voice command to their smart glasses or mobile device, as well as sharing their point of view via smart glasses' front-facing camera. VitalStream streams live vital signs and alarms to the anesthesiologist or circulating nurse's smart glasses or tablet during conscious sedation procedures to improve situational awareness."

Status: Evolving

Funding: $\$ 925,000$ in seed funding from angel investors and the Stanford StartX Fund

Product link: https://www.vitalmedicals.com/

Source: Healthcare Wearable Maker VitalMedicals Raises $\$ 925 \mathrm{~K}$ in Seed Funding http://www.iamwire.com/2015/02/vitalmedicals-raises-925k-seed-funding-angel-investors-stanford$\underline{\text { startx-fund/109476 }}$

\subsubsection{Vuzix, HeadApp: Glass4Flight}

Technology name: Glass4Flight with VuzixM100 Smart Glasses

Description: Vuzix partnered with HeadApp to create the Glass4Flight application, which integrates with WiFly, a system that give pilots "immediate access to a host of real time data points together in one handy package known as the Virtual Glass Cockpit. The Virtual Glass Cockpit creates a whole new breed of user experience for pilots, and allows for ready access to all that important material a pilot needs, including things like route information, heading, speed and altitude, among a host of others. Plus, all that information can be had on a hands-free basis, allowing the hands to remain on the controls." Vuzix glasses offer compatibility with a smartphone, HD camera, Bluetooth and wifi connectivity, integrated head tracking and GPS. HeadApp "transforms a pair of multimedia glasses into an extraordinary cockpit inspired from the 'head-up display' of military aircrafts." 
Status: Soon to be released - Anticipated to be available for purchase at the Aero2015 Expo in April 2015

\section{Funding:}

Product link: http://www.vuzix.com/consumer/products m100, http://www.headapp.eu/

Source: Vuzix and HeadApp Combine For a High-Flying Event

http://www.wearabletechworld.com/topics/wearable-tech/articles/397637-vuzix-headapp-combine-ahigh-flying-event.htm 


\subsection{Power}

\subsection{Self-powering (Harvesters)}

\subsubsection{Chinese Academy of Sciences}

Technology name: Hybridized Electromagnetic Triboelectric Nanogenerator

Description: Researchers are developing "a hybridized electromagnetic triboelectric nanogenerator for highly efficient scavenging of biomechanical energy to sustainably power wearable electronics by human walking." According to the article, "The hybridized nanogenerator exhibits a good stability for the output performance and a much better charging performance than that of an individual energy-harvesting unit." Researchers integrated the hybridized nanogenerator into a commercial shoe "to harvest biomechanical energy induced by human walking to directly light up tens of light-emitting diodes in the shoe and sustainably power a smart pedometer for reading the data of a walking step, distance, and energy consumption. A wireless pedometer driven by the hybrid nanogenerator can work well to send the walking data to an iPhone under the distance of $25 \mathrm{~m}$. This work pushes forward a significant step toward energy harvesting from human walking and its potential applications in sustainably powering wearable electronics."

Status: Evolving

Funding: This work was supported by the National Natural Science Foundation of China (Grant Nos. 51472055 and 61404034), the "thousands talents" program for the pioneer researcher and his innovation team, China.

\section{Product link:}

Source: Hybridized Electromagnetic Triboelectric Nanogenerator for Scavenging Biomechanical Energy for Sustainably Powering Wearable Electronics

http://pubs.acs.org/doi/pdf/10.1021/nn507455f

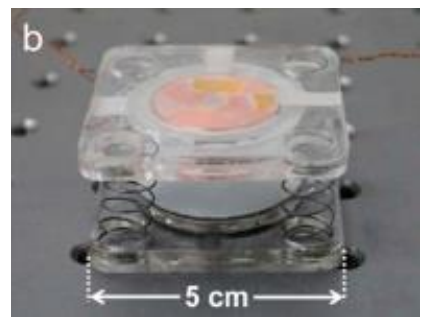

Photo Source: http://pubs.acs.org/doi/pdf/10.1021/nn507455f

\subsubsection{HSG-IMIT Institute of Micromachining and Information Technology}

Technology name: Energy-producing shoe

Description: Engineers are developing a device that can fit inside the sole of a shoe and generate energy from walking. The device comprises "a 'shock harvester', which capitalizes upon the force of the heel hitting the ground, while secondly, the 'swing harvester' produces power by monopolizing the force 
generated while the leg is in motion." The design employs "system of magnetic fields and stationary coils. As the magnets pass the coils, a voltage is created which can be stored and used. Of course, because of the diminutive size of the generator - which needs to fit unobtrusively into the shoe - the voltage generated is incredibly small." Researchers are exploring alternative placements inside the shoe, suggesting "The act of walking would be enough to power the sensors, which could measure foot rotation, acceleration and angular velocity, to determine how fast you are travelling, what distance you have covered and in which direction." Lastly, the researchers are exploring self-tying shoes that "could use the power generated from walking to secure themselves around the feet of the wearer. However, if developed properly, they could be far more useful than the Nike gimmick, when marketed to the elderly and infirm audience."

Status: Evolving

Funding: This research (IGF-Project: 17742N) was supported by the 'Programm zur Förderung der industriellen Gemeinschaftsforschung und -entwicklung (IGF, Germany)' and by the Federal Ministry of Education and Research (BMBF, Germany) under the contract 16N11843.

Product link: http://dx.doi.org/10.1088/0964-1726/24/2/025029

Source: Green "Shock Harvester" Energy is a Shoe-In for Wearable Tech Fans http://www.pollutionsolutions-online.com/news/greenenergy/42/breaking news/green shock harvester energy is a shoe-in for wearable tech fans/33313/

\subsection{Power supplies}

\subsubsection{Ballard Power Systems}

Technology name: Fuel cell technology

Description: The fuel cell power system is anticipated to "provide similar or better performance than current wearable lithium-ion batteries while decreasing weight and volume by more than $50 \%$ for 72 -hour missions." Ballard Power Systems will bring its proton exchange membrane fuel cell technology to two new contracts. One is a non-automotive technology solutions contract with Ardica Technologies for "the next phase of an ongoing program to develop a wearable fuel cell power system for soldiers. The new work phase will focus on reducing costs and developing additional manufacturing capabilities as the Ardica system gets closer to the prototype stage." The second is an automotive technology solutions contract with an unnamed automotive original equipment manufacturer.

Status: Evolving

\section{Funding:}

Product link: http://www.ballard.com/

Source: Ballard Power Systems (BLDP) Stock Gains After Signing New Contracts http://www.thestreet.com/story/13054649/1/ballard-power-systems-bldp-stock-gains-after-signing-newcontracts.html 


\subsubsection{Sungkyunkwan University}

Technology name: Nanopatterned Textile-Based Wearable Triboelectric Nanogenerator

Description: Researchers are exploring "fully flexible, foldable nanopatterned wearable triboelectric nanogenerator (WTNG) with high power-generating performance and mechanical robustness." They were able to successfully demonstrate "the self-powered operation of LEDs, the LCD, and the keyless vehicle entry system only with the output power of our WTNG without any help from external power sources, which proves potential applications of WTNGs in self-powered smart clothes, health care monitoring and self-powered wearable devices, and even personal electronics." The researchers recognize nanogenerators "as an important new type of energy-harvesting technology that converts mechanical energy into electrical energy and have attracted great attention for realizing self-powered wearable electronics."

Status: Evolving

Funding: This work was financially supported by Basic Science Research Program and the Center for Advanced Soft-Electronics as Global Frontier Project through the National Research Foundation of Korea Grant funded by the Ministry of Science, ICT \& Future Planning.

\section{Product link:}

Source: Nanopatterned Textile-Based Wearable Triboelectric Nanogenerator http://pubs.acs.org/doi/full/10.1021/nn507221f 

PNNL RTA Monthly Report Communications

\subsection{Communications}

\subsection{Short-range, low-power Bluetooth}

\subsubsection{Automated Assembly Corporation: InfoSkin}

Technology name: InfoSkin near-field communications (NFC)

Description: InfoSkin is a line of NFC tags that adhere to the skin or other surfaces and are "aimed at the healthcare industry where they would be used to improve patient care by making it easier for staff to update treatment records and create automatic time stamps for patient activities." The device employs Automated Assembly's patent-pending wire write technology that uses copper wire rather than a flexible etched circuit to be flexible, comfortable, and green with improved NFC range and improved ability to be read at different angles.

Status: Evolving

Funding:

Product link: http://www.autoassembly.com/infoskin-wearable-nfc-tag/

Source: AAC to mass produce wearable NFC stickers for healthcare http://www.nfcworld.com/2015/02/17/334156/aac-to-mass-produce-wearable-nfc-stickers-for-healthcare/

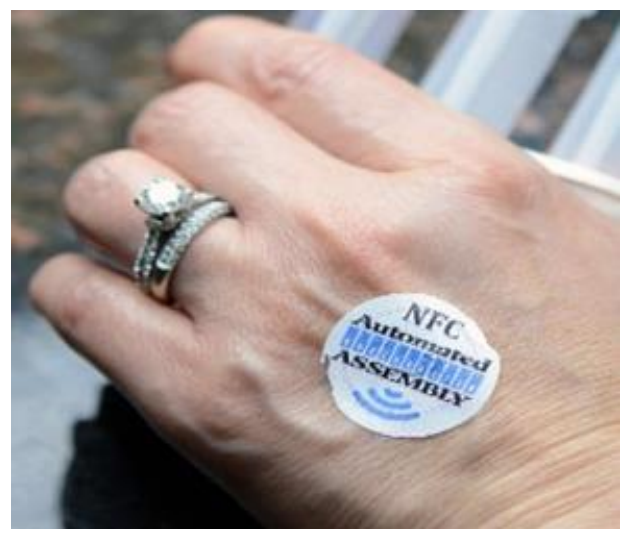

Photo Source: http://www.autoassembly.com/infoskin-wearable-nfc-tag/

\subsubsection{FreeWavz}

Technology name: FreeWavz wireless smart earphones

Description: FreeWavz wireless smart earphones are "fitness bands for the ears" with the capability to communicate wireless to the user via Bluetooth, measure heartrate, and report and provide audio alerts regarding calories burned, distance, and steps while also playing music, with the added capability of configurable listen-through to "blend between sound from the smartphone and the surrounding environment can be adjusted to match the wearer's preferences." The earphones employ Bluetooth to eliminate the need for wires or physical connection to the device. 
Status: Soon to be released

Funding:

Product link: http://www.freewavz.com/

Source: FreeWavz Wirefree Wearable Earphones

http://geeknewscentral.com/2015/02/06/freewavz-wirefree-wearable-earphones-progress/

\subsection{Hands-free operation}

\subsubsection{RHL Vision Technologies Pvt. Ltd.: Fin}

Technology name: Fin thumb ring

Description: The Fin thumb ring connects with "innumerable devices via Bluetooth and allows the user to control them by simply moving the ringed finger on the palm." Developers leveraged the thumb because "the thumb is the only finger that can move everywhere on the palm." Different points on the palm serve as the menu, keypad, or gesture space, providing options for smart phone, keypad, reading, calendar, head-mounted display, and various other modes.

Status: Soon to be released

Funding: Crowdfunding - doubled the $\$ 100,000$ pledge target

Product link: http://www.finrobotics.com/

Source: FIN - the thumb-ring that aims to take human-machine interaction to the next level http://yourstory.com/2015/02/fin/
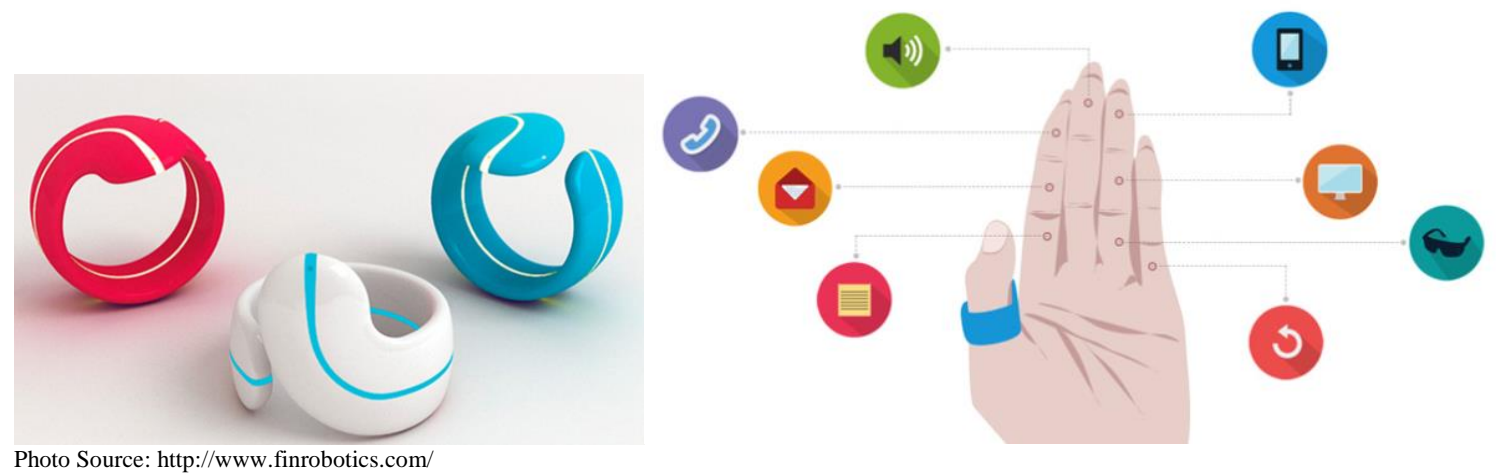


\subsection{Cameras}

\subsubsection{Contour: ContourGPS}

Technology name: ContourGPS

Description: The ContourGPS Action video Camera is equipped with GPS technology to track location, speed and altitude multiple times per second, while capturing high-definition video. The lightweight (4.3 ounces) device shoots 1080p video and features 135-degree angle lens, live streaming, still photo mode, and GPS video mapping that connects to smart devices.

Status: Available

\section{Funding:}

Product link: http://contour.com/

Source: ContourGPS Wearable Camera

http://winecountrymotorsports.com/contourhd/contourgps-wearable-camera-p-879.html

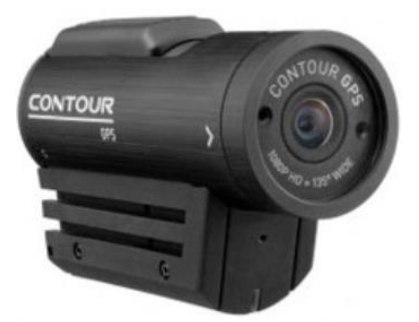

Photo Source: http://contour.com/

\subsubsection{Digital Ally}

Technology name: Wearable cameras

Description: Digital Ally specializes in advanced digital video police cameras, fleet records and law enforcement surveillance equipment, as well as sports cameras (surf, ski, etc.). Digital Ally competes with wearable cameras such as GoPro in the field of "selling cameras worn by law enforcement offers to record field situations." Digital Ally recently filed a patent for "breath analyzer system and computer program for preserving breath analysis data."

Status: Evolving

\section{Funding:}

Product link: http://www.digitalallyinc.com/

Source: Why Digital Ally May Get More Orders From The Gov't 
http://news.investors.com/business/022315-740418-digital-ally-shares-jump-gsa-award.htm

\subsubsection{First V1sion}

Technology name: First V1sion camera garment

Description: This camera-equipped t-shirt fitted with "a small high-definition camera with an optical lens and a sports jersey with biometric sensors throughout. The biometric sensors gather information with an Intel Edison chip, allowing the shirt to send player data to computers via WiFi." The camera offers "broadcast quality" 1080p/24FPS and 720p/50FPS resolution, video capability, optional microphone, PAL or NTSC format, and radiofrequency transmission.

Status: Evolving

\section{Funding:}

Product link: http://www.firstv1sion.com/

Source: First V1sion Wants to Bring Wearable Cameras to Broadcasts http://news.wearables.com/first-v1sion-wants-to-bring-wearable-cameras-to-broadcasts/

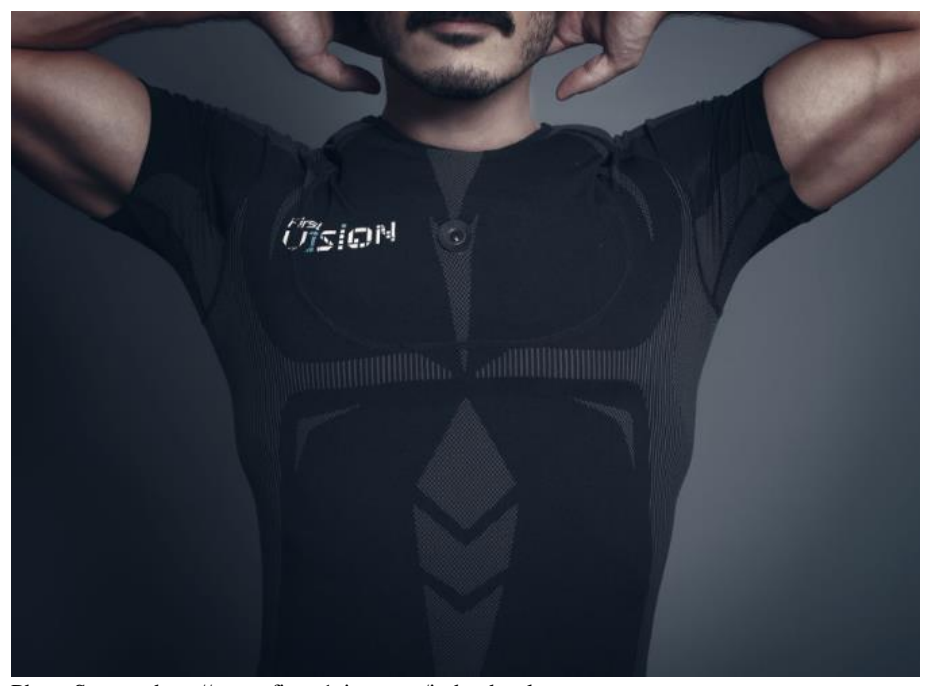

Photo Source: http://www.firstv1sion.com/index.html

\subsubsection{Marantz}

Technology name: PMD-901V video recorder

Description: Marantz developed a "personal video recording device that is wearable and can be used by service workers and first responders like police and fire fighters to record their daily activities. The Marantz PMD-901V is a GPS enabled portable video recorder. It captures full HD video and can capture a full work day of video for workers in a variety of situations." According to the product press release, "With 32GB of secure, tamper-proof internal storage, the PMD-901V captures up to 8 continuous hours of full HD video at 2304 x 1296 resolution, rendering impeccable detail and clarity, in harsh conditions. Weighing less than 7 ounces, the PMD-901V attaches unobtrusively to the user's clothing with a swiveling clip for optimum video capture from the ultra-wide 140-degree field-of-view lens. The internal 
GPS receiver provides automatic location tagging of video- and still-captures, offering irrefutable substantiation of where and when the audio and video were recorded." The device features waterproof construction, submersible for up to 30 minutes at $1 \mathrm{~m}$, night-vision, ability to withstand temperatures between -40 to 140 degrees F, and "intuitive, one-handed operation - even while wearing gloves."

Status: Soon to be released

\section{Funding:}

Product link: http://denonpro.com/assets/microsites/CES2015/press releases/english/PMD901V.pdf

Source: Marantz Brings Affordable Wearable Video Recording for Responders http://tpn.tv/2015/02/07/marantz-brings-affordable-wearable-video-recording-for-responders/

\subsubsection{MeMini}

Technology name: meMini wearable camera

Description: meMini is a body-worn camera that constantly films: "When wearers of the camera press a button on the device, the previous minute of film is saved. The special moment is captured, rather than lost in the time it takes to fumble for the camera or smartphone." The camera employs the developer's new "Recall" technology as well as 1080HD capability, 140-degree field of view, 30 frames per second shooting, Sony 8 megapixel image sensor, wifi and Bluetooth capability, and 3.5 hour battery life. It streams to a smartphone to set the recall time and review/manage footage.

Status: Soon to be released - Manufacturing planned for April

Funding: Crowdfunding, incubator

Product link: http://memini.com/

Source: Tiny camera inventor draws global praise http://www.stuff.co.nz/technology/gadgets/65856243/tiny-camera-inventor-draws-global-praise

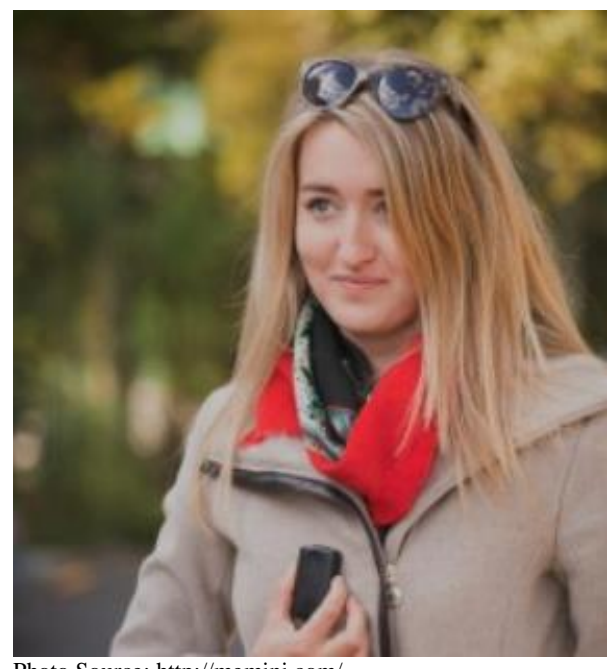

Photo Source: http://memini.com/ 


\subsubsection{QindredCam}

Technology name: QindredCam

Description: QindredCam is a clip-on camera that shoots photo and video and offers built-in intelligence (sensors and software) and cloud service to manage and share content. The camera is 8 megapixel with a wide-angle lens. When the device connects to wifi, "all the photos and videos you take are sent to the cloud. There, they will be organized and edited for you and your loved ones to enjoy on our Qindred mobile app or any browser. The 'Highlight' option on the app will only show you the best photos or videos, as refined by our Cloud Service. Once your moments are safely stored in the cloud, you can privately share them with your family and friends." The device features weather-proof casing, noisecancelling mic, interchangeable magnet/clip options, wifi and Bluetooth capability, USB port, 4GB storage, and 10-15 hour battery life.

Status: Evolving

Funding: Crowdfunding

Product link: http://www.acumulus9.com/qindredcam/

Source: QindredCam: The Intelligent Wearable Camera https://www.kickstarter.com/projects/1810705046/qindredcam-the-intelligent-wearablecamera?ref=newest

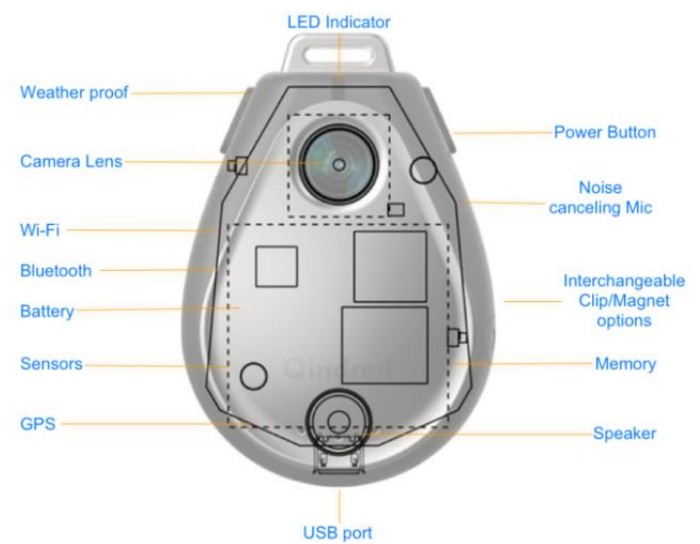

Photo Source: https://www.kickstarter.com/projects/1810705046/qindredcam-the-intelligent-wearable-camera

\subsubsection{Swann: Bolt HD}

Technology name: Bolt HD wearable action camera

Description: This camera's capabilities features include high definition video recording, 12 mega-pixel still camera, MicroSD, mounts, and remote control. According to the product web site, the device can:

- Record professional high definition action videos at 1080p (1920 x 1080 pixels $)$ in real time (30fps) with stereo audio

- Use the laser point to check the camera is on target \& shoot in any conditions with waterproof casing to $32 \mathrm{ft} / 10 \mathrm{~m}$ below the surface

- Re-live the action in high definition with mini HDMI connection (cable not included)

- Record footage to MicroSD card (up to 32GB), or use the USB cable to transfer to PC or Mac for easy uploading to your favorite websites 
- Convenient lithium-ion battery is rechargeable from USB with 1.5 hours recording per charge

- Includes wearable mounts to catch the best angle

- Create hands-free action video while cycling, mountain biking, motorbike riding, car driving, skiing, snowboarding, surfing, swimming, running, walking, rafting, skydiving or enjoying any adrenaline-pumping activity

Status: Available

\section{Funding:}

Product link: http://www.swann.com/us/swvid-sportw

Source: Bolt HD - Wearable Action Camera

http://www.swann.com/us/swvid-sportw

\subsubsection{Vievu}

Technology name: Vievu cameras

Description: Vievu produces a range of wearable cameras providing real-time streaming, HD video, built-in wifi, pairing with smartphone, military-grade anodized aluminum housing, and other capabilities. Vievu is a "small, lightweight camera that can be mounted almost anywhere. Vievu cameras can be connected to either smartphones (via the Vievu app), laptops, or IP networks. [. . .] Vievu cameras can capture both audio and video in resolutions of either 1080p, 720p or 360. Cameras come with 16GB of internal storage and they can record for about 2.5 hours or stream for about 90 minutes before needing a recharge."

Status: Available

\section{Funding:}

Product link: http://www.vievu.com/vievu-products/hardware/

Source: Vievu Brings Wearable Cameras to CES

http://geeknewscentral.com/2015/02/06/vievu-wearable-cams-ces/ 

PNNL RTA Monthly Report

Breathing Apparatus

\subsection{Breathing Apparatus}

\subsubsection{Scott}

Technology name: Scott self-contained breathing apparatus

Description: The Monroe Fire Department is training with the Scott self-contained breathing apparatus. The device is "equipped with Pak-Tracker, which will allow for faster location of a downed firefighter. With the newly designed sweep gauge, the user can easily monitor air supply."

Status: Available

Funding:

Product link: https://www.scottsafety.com/en/us/Pages/Default.aspx

Source: MFD trains with new safety equipment

http://www.thenewsstar.com/story/news/local/2015/02/18/mfd-trains-new-safety-equipment/23616349/ 

PNNL RTA Monthly Report

Exoskeletons

\subsection{Exoskeletons}

\subsubsection{Hiroshima University: Sensorimotor Enhancing Suit}

Technology name: Sensorimotor Enhancing Suit

Description: The Sensorimotor Enhancing Suit is "muscle assistive equipment" that "enhances sensorimotor functions by reducing the muscle load of the upper limbs." The device reduces cost through the use of flexible fabrics using regular cloth and by not including any electronic devices. SENS "assists human sensorimotor functions and improves the quality of life of not only elderly individuals but also healthy people who work under extreme conditions."

Status: Evolving

\section{Funding:}

Research link: DOI: 10.1145/2582051.2582055

Source: New assistive equipment to maximize human sensorimotor function http://medicalxpress.com/news/2015-02-equipment-maximize-human-sensorimotor-function.html

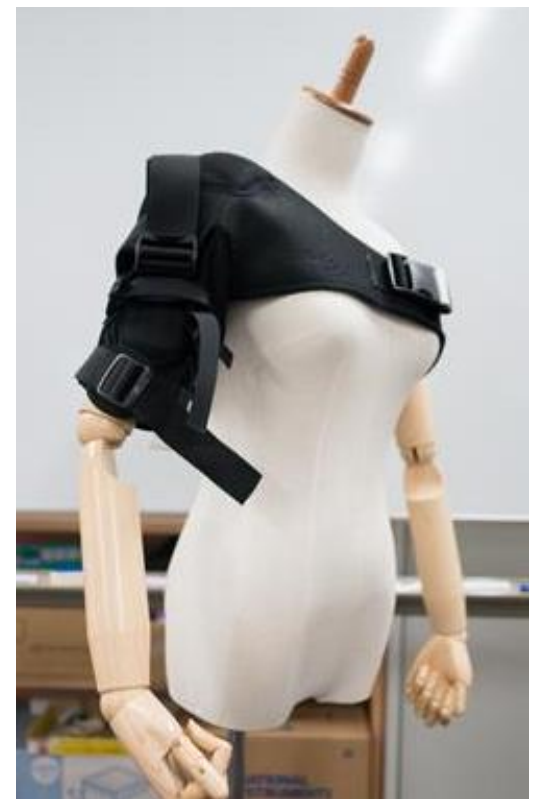

Photo Source: http://medicalxpress.com/news/2015-02-equipment-maximize-human-sensorimotor-function.html

\subsubsection{University of Bristol}

Technology name: Smart trousers

Description: These "smart trousers" use artificial muscles to assist mobility and "could even replace stairlifts and wheelchairs." The device uses "artificial muscles made from smart materials and reactive plastic-like molecules capable of exerting great forces. Control systems will be incorporated that monitor 
the wearer and work with the body's own muscles to provide assistance when needed. The system could help vulnerable people avoid falls, provide the added strength needed to move between sitting and standing, and make it easier to climb stairs."

Status: Evolving

Funding: $£ 5.3 \mathrm{~m}$ from the Engineering and Physical Science Research Council

\section{Product link:}

Source: UK robotics experts developing 'smart trousers'

http://www.theguardian.com/technology/2015/feb/24/uk-robotics-experts-developing-smart-trousers 
PNNL RTA Monthly Report

Wearable Computers

\subsection{Wearable Computers}

\subsubsection{Blu}

Technology name: Wearable smartphone

Description: Blu is a flexible, wearable smart phone, utilizing a flexible organic light-emitting display (OLED), overlapping clasp, with a light bar on each side of the wristband, $5 \times 2$ inch display, speakers for "360 degrees of sound," Gesture Orientation User Interface, and wireless capability. The device is equipped "with a wireless dock for recharging and file transfer via wireless power transmission and nearfield communication adaptable via USB to PC or power outlet."

Status: Evolving

Funding: Crowdfunding

\section{Product link:}

Source: Blu: Wearable Smartphone

https://www.kickstarter.com/projects/516521822/blu-wearable-smartphone/

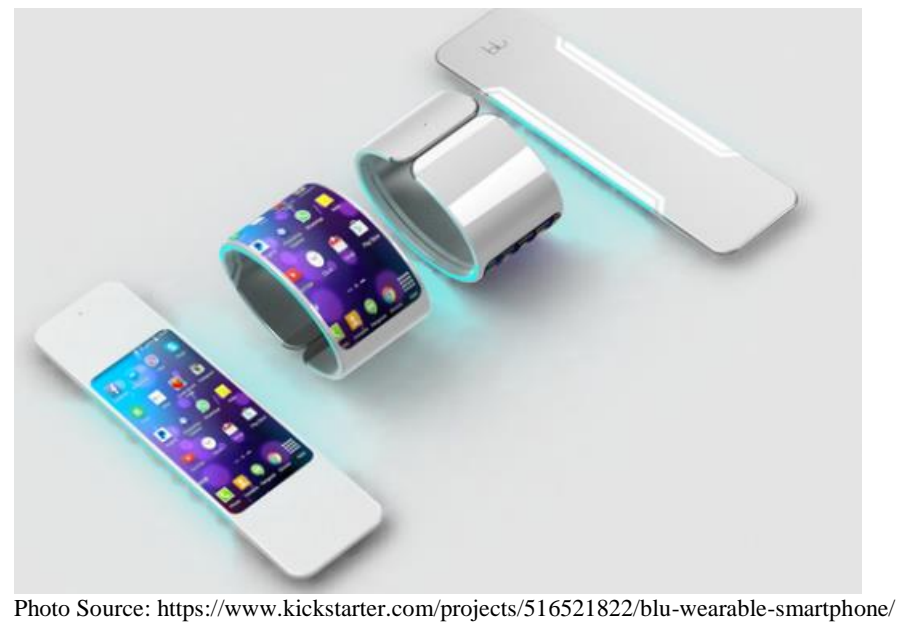

\subsubsection{Neptune: Duo}

Technology name: Duo wearable computer

Description: Duo is a wearable computer that features "a Hub, a bangle style wearable computer, will allow users to make calls and text messages, check into various social networking sites, track fitness data, and more from their wrist. The companion 'Pocket' screen, which looks like a smartphone, acts as a keyboard, track pad or monitor." The Android device comprises the Hub and the Pocket: "The Hub includes a 2.4-inch capacity touch screen. It will house a quad-core processor with 64GB onboard storage, Bluetooth 4.0, NFC, and GPS. It will support 3G and 4G LTE, as well as $802.11 \mathrm{Wi-Fi}$ connectivity. It also includes a speaker, microphone, and vibration monitor, as well as an accelerometer, gyroscope, and digital compass. [ . . . ] The Pocket is a second screen interface with a five-inch $1280 \mathrm{x} 720 \mathrm{HD}$ resolution 
display. It features an 8 megapixel rear-facing camera with LED flash and a 2 MP front-facing camera with It has a port for headphones, and also includes a speaker, microphone, and vibration monitor, as well as an accelerometer and gyroscope." The device also "doubles as a battery pack. If the Hub runs low on juice, the Pocket will be able to recharge it. The developers claim the Duo will be able to last a few days of normal use on a single charge."

Status: Evolving

Funding: Crowdfunding

Product link: http://www.getneptune.com/

Source: Neptune Duo is a full-featured wearable computer with a phone-like display http://liliputing.com/2015/02/neptune-duo-is-a-full-featured-wearable-computer-with-a-phone-likedisplay.html

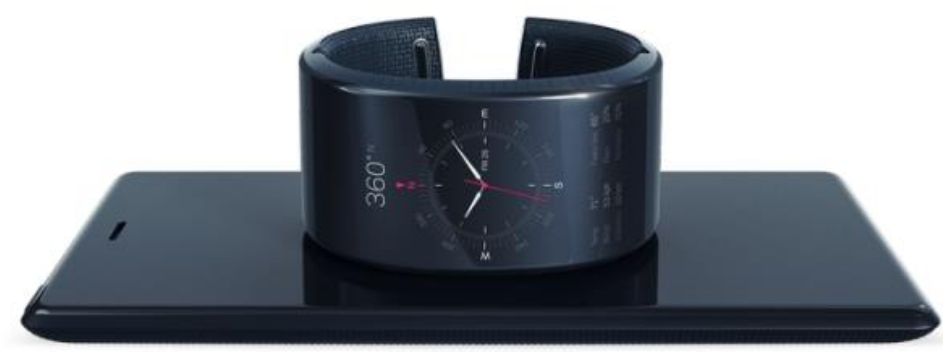

Photo Source: http://www.getneptune.com/

\subsubsection{Samsung: Orbis}

Technology name: Orbis smartwatch

Description: The Orbis smartwatch features a round metal case device, which operates by "rotating bezel to the left will help you to explore the notification center and identify that you are searching for. Rotating the bezel to the right will reject a call from your smartphone." It is anticipated the device "will have also a crown button like the Apple Watch with rotate and press function like close recent applications or close call. Another function of the rotating bezel is to change music track when the music app is opened or to dismiss the morning alarm." The device is anticipated to feature a wireless charging system and curved OLED display; the operating system is not determined at this time.

Status: Evolving

\section{Funding:}

\section{Product link:}

Source: Samsung Orbis challenge the wearable market with new features http://www.flexible-display.net/samsung-orbis-challenge-wearable-market-new-features/ 
PNNL RTA Monthly Report Wearable Computers

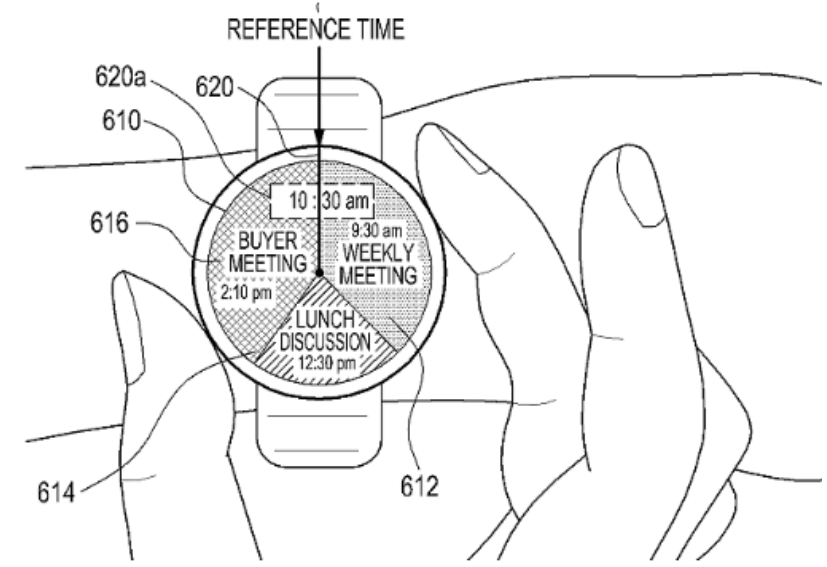

Photo Source: http://www.flexible-display.net/wp-content/uploads/2015/02/Samsung-Orbis-smartwatch-1_opt.png 



\subsection{Other}

\subsubsection{Avon Protection, SecureBio, Ltd.}

Technology name: Personal protective equipment (PPE) with NH15 escape hood

Description: The new line of PPE is designed to address chemical, biological, radiological and nuclear threats and features Avon's NH15 hood, which is an NIOSH certified CBRN Air Purifying Escape Respirator. The new PPE offers respiratory protection, suits, gloves and personal decontamination solutions, and biological and explosives detection. Avon also announced it will provide "support services to security teams for major global events. This would include consultation and equipment to facilitate proper response for CBRN and hazardous materials-related threats or attacks."

Status: Evolving

Funding:

Product link:

Source: Avon Protection unveils new PPE technology

http://bioprepwatch.com/news/avon-protection-unveils-new-ppe-technology/340930/

\subsubsection{Boogio}

Technology name: Boogio footwear pressure sensors

Description: Boogio is a "sticker that you put underneath an insole that has pressure sensors across toe heel and arch, with 65,000 layers of pressure sensitivity. A small device clips to the side of the shoe and contains a gyroscope, 3D accelerometer, Bluetooth connectivity, and battery. Boogio generates a lot of data points such as the weight of your body on your feet, how you are holding yourself up when standing, and can infer from your inner balance when shifting weight from left to right." Researchers are exploring applications for occupational and health monitoring applications, as well as "benefits of gait output which is really a neurological output and therefore early indicators of Parkinson's or Alzheimer's disease."

Status: Evolving

Funding:

Product link: https://boogio.com/

Source: IoT Shoe Insert Connects Gait To Digital Worlds http://www.forbes.com/sites/robertvamosi/2015/02/13/iot-shoe-insert-connects-gait-to-digital-worlds/ 


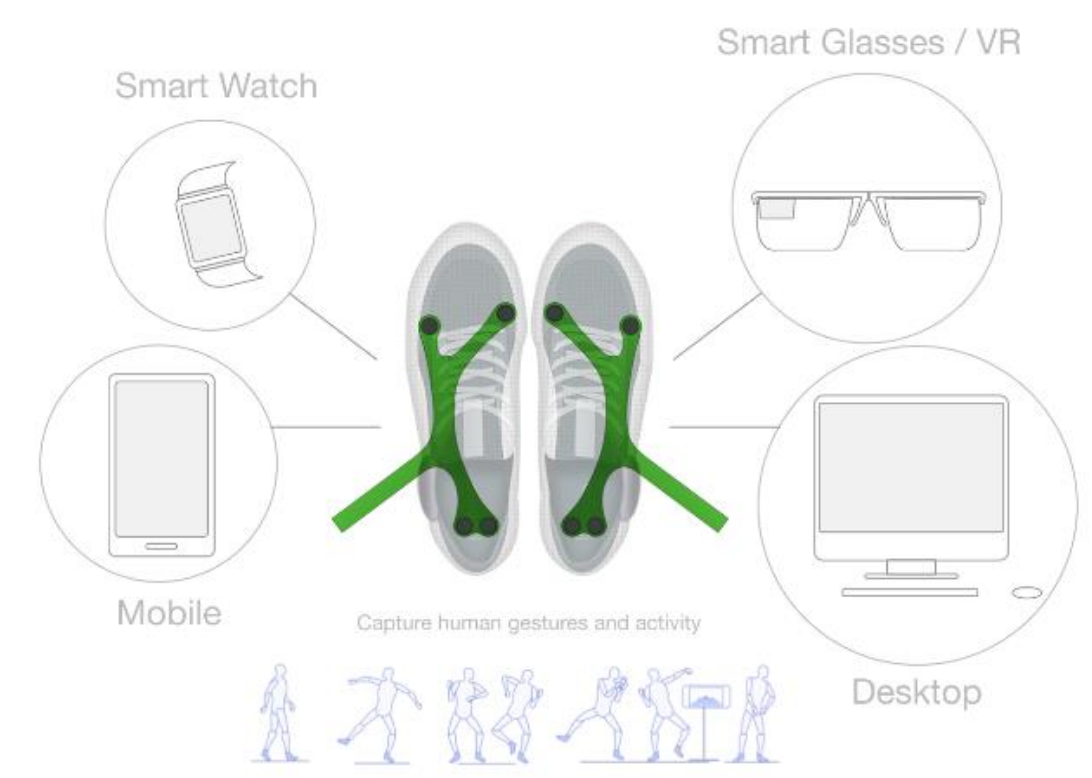

Photo Source: https://boogio.com/

\subsubsection{Broadcom}

Technology name: Smartwatch platform

Description: The Broadcom smartwatch platform "reduces power consumption by up to $40 \%$ (over the previous generation) for Android Wear devices." The platform includes a wearable system-on-a-chip, wifi and Bluetooth connectivity, NFC, and wireless charging. The platform offers "smaller form factor, enabling original equipment manufacturers to add more features or include a larger battery inside their wearable to allow for even longer time between charges. In addition to an advanced application processor and Broadcom's leading Wi-Fi and Bluetooth combo chip in the new platform, original equipment manufacturers can choose to integrate GPS with sensor hub processing, near field communication, wireless charging support and camera support based on their product needs." Broadcom is the creator of the Wireless Internet Connectivity for Embedded Devices that allows "two devices to communicate with each other securely via Wi-Fi without an access point or computer."

Status: Evolving - now sampling

\section{Funding:}

Product link: http://www.broadcom.com/press/release.php?id=s898227

Source: Broadcom Launches A New Smartwatch Platform For Android Wear Devices http://www.forbes.com/sites/greatspeculations/2015/02/27/broadcom-launches-a-new-smartwatchplatform-for-android-wear-devices/

\subsubsection{Dainese: D-Air Ski}

Technology name: D-Air Ski wearable airbag 
Description: Dainese is developing a wearable airbag for skiing that is a vest that "uses internal sensors including gyroscopes, accelerometers, and a GPS system to sense when a skier is toppling, deploying the airbag if speed and angle suddenly change. The design is relatively lightweight, made of materials similar to moisture-wicking shirts and carrying an onboard computer about the size of a credit card. The vest is single use, designed specifically with professional skiers in mind.” The device is powered by a rechargeable lithium-ion battery and reportedly does not impact aerodynamics. Dainese has already created wearable airbags for motorbiking.

Status: Evolving

\section{Funding:}

Product link: http://www.dainese.com/us_en/

Source: Wearable Airbag Could Save Skiers Lives - If They Would Just Wear It http://www.popularmechanics.com/adventure/sports/a14013/this-skiing-airbag-could-save-olympianlives/

\subsubsection{Eccrine Systems}

Technology name: Sweatronics ${ }^{\mathrm{TM}}$ disposable sweat-monitoring device

Description: Eccrine Systems is developing a "sweat-monitoring device [that] can constantly test sweat to provide insights into the human body it will then transmit wirelessly into the cloud" and could be made available to a patient's physicians. Eccrine Systems' Sweatronics ${ }^{\mathrm{TM}}$ platform is a "modular, flexible system about the size of a larger Band-Aid that is capable of measuring multiple different analytes in sweat and wirelessly transmitting data via a transceiver to remote applications." The device features radiofrequency identification and Bluetooth capabilities, as well as a software development kit to interface with a range of devices. Developers anticipate the device can have applications in "healthcare, including medication adherence, measuring individual drug effectiveness and helping optimize the performance of military personnel, among other things" including alerting physicians when patients miss medications or dehydration occurs.

Status: Evolving

Funding: 1.5 million in private investment from the regional group CincyTech and other Cincinnati-area partners.

Product link: http://www.eccrinesystems.com/

Source: Can sweat tests be better than blood tests (thanks to wearable tech)? http://medcitynews.com/2015/02/sweat-test-alternative-blood-test/ 


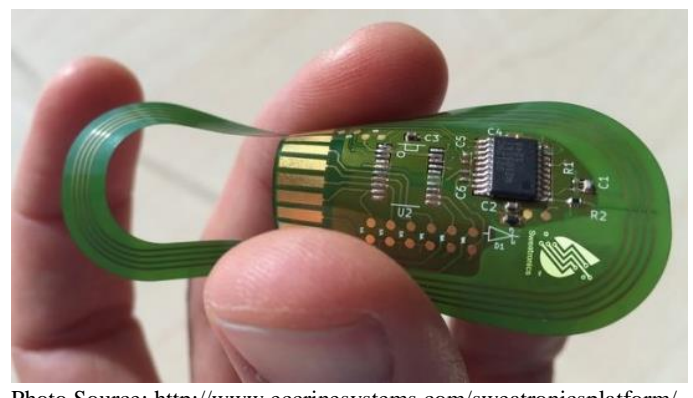

\subsubsection{Hanyang University}

Technology name: Multiferroric materials

Description: Researchers from South Korea are exploring "more bendable devices by manufacturing a thin film that keeps its useful electric and magnetic properties even when highly curved." Researchers successfully "synthesized nanoparticles of bismuth ferrite and mixed them into a polymer solution. The solution was dried in a series of steps at increasing temperatures to produce a thin, flexible film. When the researchers tested the electric and magnetic properties of the film they found that their new material did much more than preserve the useful properties of bulk bismuth ferrite - it actually made them better. And the improved properties remained even as the film was curved into a cylindrical shape." Researchers propose that "flexible multiferrorics could enable new wearable devices such as health monitoring equipment or virtual reality attire" as well as "use in high-density, energy efficient memory and switches in such devices."

Status: Evolving

\section{Funding:}

\section{Product link:}

Source: Film Key to Curved Wearable Devices

http://www.laboratoryequipment.com/news/2015/02/film-key-curved-wearable-devices

\subsubsection{Heddoko}

Technology name: Heddoko smart garment

Description: The Heddoko smart garment tracks movement in 3D and provides users visual feedback and analysis via an app. Sensors in the fabric measure arms, legs, chest, back, and stomach and can provide real-time feedback and statistical analysis. The device provides live training feedback with 3D visuals that help a user visualize and analyze their performance. Wearers can use the data to adjust movements, and potentially compare it to another model, in order to improve performance, reduce risk from improper ergonomics, etc.

Status: Evolving

\section{Funding:}


Product link: http://www.heddoko.com/

Source: Heddoko Is a Smart Garment That Gives Athletes 3D Visuals About Their Movements http://www.sporttechie.com/2015/02/27/heddoko-is-a-smart-garment-that-gives-athletes-3d-visualsabout-their-movements/

\subsubsection{Hitachi}

Technology name: Happy-measuring wearable

Description: Hitachi is developing a "card-size device equipped with an acceleration sensor that monitors a group's behavior and sends data to cloud-based servers. The card collects data 50 times a second and detects certain types of actions from various types of movement such as walking, nodding and typing. It then uses the data it has collected to interpret the group's overall mood." Hitachi reports the service will be available on a subscription basis with an annual fee.

Status: Evolving

\section{Funding:}

Product link: http://www.hitachi.co.jp/New/cnews/month/2015/02/0209.html (in Japanese)

Source: Hitachi develops a Wearable Technology that Unlocks the Key to Happiness http://fareastgizmos.com/wearable/hitachi-develops-wearable-technology-unlocks-key-happiness.php

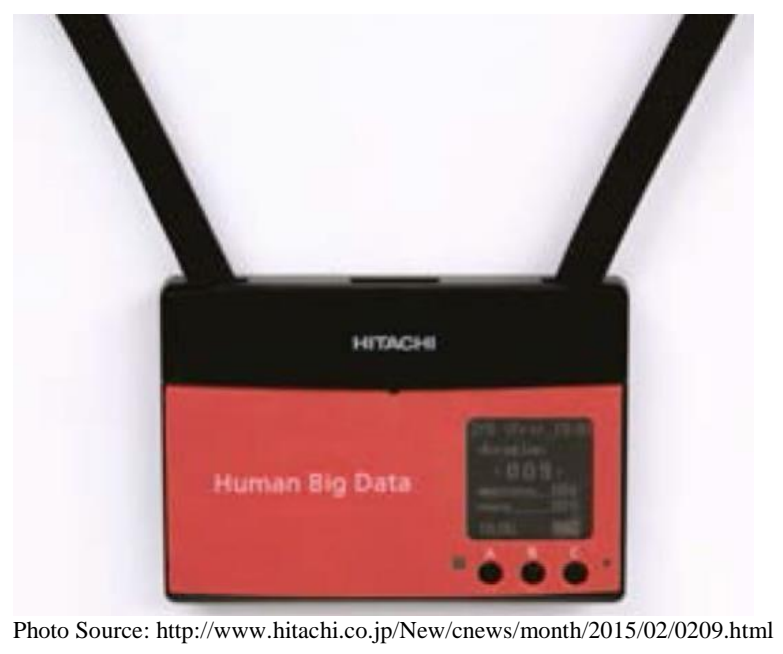

\subsection{2 iGel}

Technology name: iGel full-body airbag suit

Description: The iGel full-body airbag suit is a "hedgehog-inspired" full-body airbag that "would use up to 20 individual nitrogen-activated airbags to protect the head, torso and lower body." The developer proposes "the actuation of the system pushing the torso and lower body into a fetal-style ball, further helping to mitigate against injury. [. . . Like other airbag systems, the iGel would use a series of microelectromechanical system smart sensors to detect crash-level forces and automatically inflate around 
the wearer." The developer is also exploring "using long-distance sensors like radar and supersonic sensors to equip the suit with the ability to sense a crash ahead of time, similar to how automakers use such sensors to prevent crashes during adaptive cruise control operation and other semi-autonomous operations."

Status: Evolving

\section{Funding:}

Product link: http://www.igel-systems-protect.de/

Source: Hedgehog-inspired full-body airbag would inflate into a personal safety cocoon http://www.gizmag.com/hedgehog-inspired-full-body-airbag/35994/

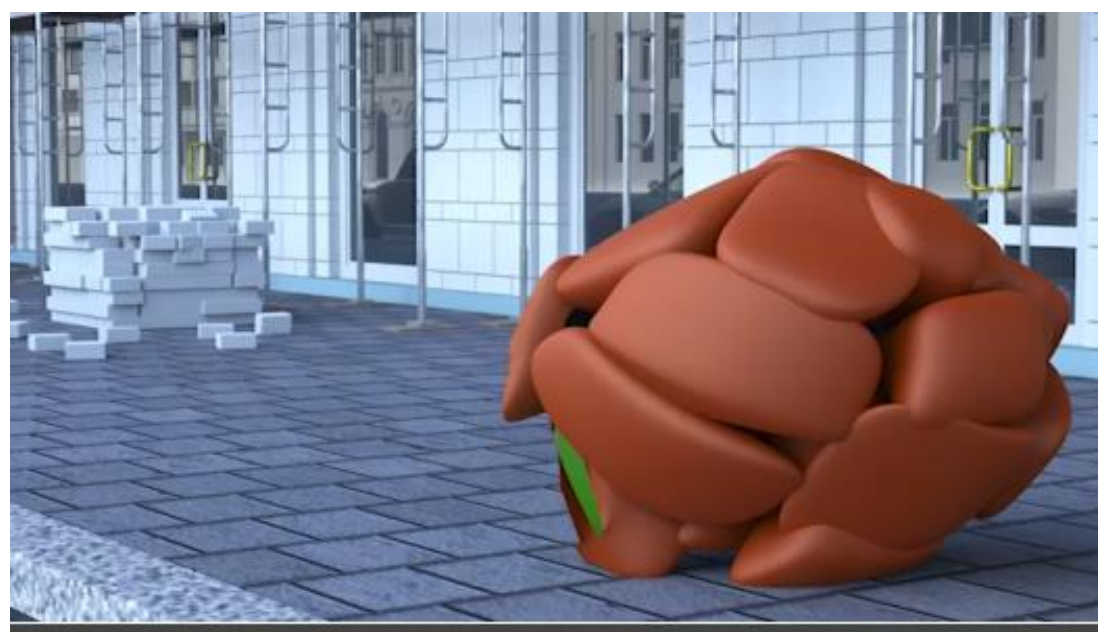

In this rendering, the i Gel protects someone falling off a building by

pushing him into a ball and inflating airbags all around him

Photo source: http://www.gizmag.com/hedgehog-inspired-full-body-airbag/35994/

\subsubsection{Immersion Corporation: Instinctive Alerts Framework}

Technology name: Instinctive Alerts Framework

Description: The Instinctive Alerts Framework is a "scalable solution for designing a wearable device that effectively and privately communicates to users through tactile effects, without requiring any additional audio or visual context." The device uses distinct alerts "Now This, Know This, Do This, and Review This, as well as a fifth category, Changed This." The framework's tactile effects are "designed to intuitively direct user response from the first use and provide a natural learning curve for understanding the specific meaning of the alerts over time. For example, a notification that is time sensitive and urgent, like an incoming phone call, may have a more rapid and noticeable tactile effect as a part of the Now This category, whereas a subtler Review This effect could communicate the receipt of a less pressing email." Users can learn up to 40-70 different alerts. The device features Immersion's TouchSense ${ }^{\circledR}$ Core ${ }^{\mathrm{TM}}$ which "offers device makers the ability to create a high quality, consistent user experience, and their own unique tactile-enhanced device features."

Status: Evolving 


\section{Funding:}

\section{Product link:}

Source: Immersion Redefines Wearables Communication With Instinctive Alerts Framework http://www.businesswire.com/news/home/20150226005295/en/Immersion-Redefines-WearablesCommunication-Instinctive-Alerts-Framework\#.VO81oE0cRmM

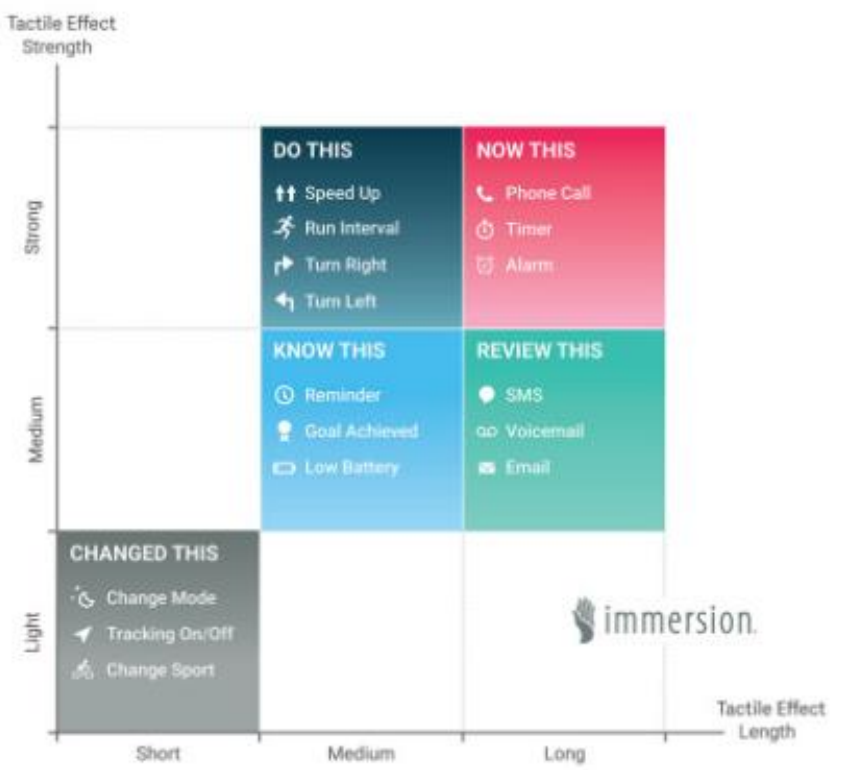

Photo source: http://www.businesswire.com/multimedia/home/20150226005295/en/\#.VPobwk0cRYU

\subsubsection{Intel: RealSense}

Technology name: RealSense environmental sensing system

Description: TheRealSense environmental sensing system is designed for visually impaired users and "consists of a camera and six sensors attached to various points of a jacket. As objects or people approach the wearer, the sensors on the shirt detect the distance and direction of said object and vibrate, thus giving the wearer a sense of their immediate environment and letting them take necessary action." The device is anticipated to be made available open source later this year, allowing others to build on and improve the technology.

Status: Evolving

Funding:

Product link: http://iq.intel.com/realsense-3d-camera-technology-help-people-cant-see/

Source: A Wearable That Can Help Blind People Understand Their Surrounding http://www.assistivetechnologyblog.com/2015/02/a-wearable-that-can-help-blind-people.html 


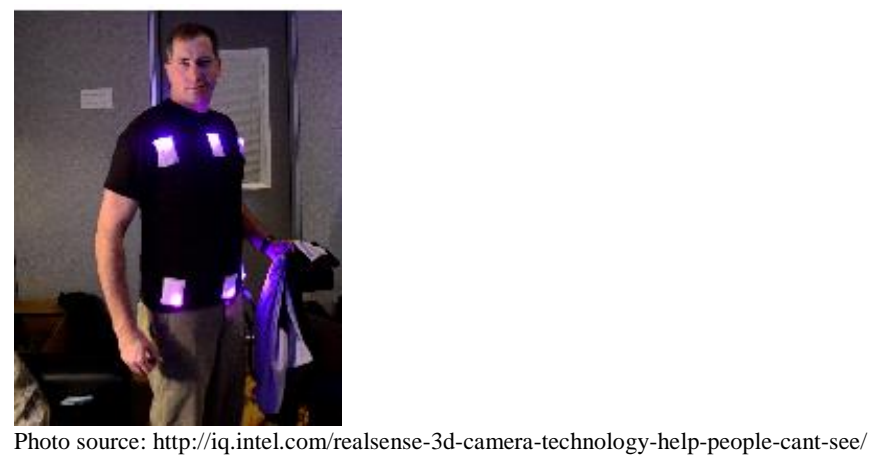

\subsubsection{JOT Automation: JOTG3}

Technology name: JOTG3 smartphone testing platform

Description: JOTG3 is a product-testing system for smart phones that allows users to "run tests on radio frequency material, as well as electrical systems, mechanical systems, touchscreen and buttons, audio, and even plug-in connections to help make sure everything works according to Hoyle, so to speak, before getting released into a wider radius." With so many new products coming to market, JOTG3 offers "a platform from which a variety of tests can be run and the chances of a successful release can climb accordingly."

Status: Evolving

\section{Funding:}

Product link: http://www.jotautomation.com/en/products-solutions/test-handlers-and-solutions.html

Source: JOT Automation Develops Automated Test System for Wearable Devices http://www.wearabletechworld.com/topics/wearable-tech/articles/398021-jot-automation-developsautomated-test-system-wearable-devices.htm

\subsubsection{Kelvin Thermal Technologies, University of Colorado}

Technology name: Thermal management technologies

Description: Kelvin Thermal Technologies and the University of Colorado are partnering to develop "thermal management technologies that could enable the development of ultra-thin and flexible smartphones, wearable electronics and other commercial and military systems." Researchers developed "a flat, heat-transfer device as thin as a credit card that can be mounted on electronic devices -- a new approach to thermal management that replaces conventional materials like graphite, copper and aluminum used to remove heat from devices." The device is estimated to be "at least three times as efficient as graphite and ten times as efficient as copper," ultra-thin, and flexible.

Status: Evolving

Funding: Funding from the U.S. Department of Defense under its Defense Advanced Research Projects Agency (DARPA), contract number N66001-08-C-2006 


\section{Product link:}

Source: CU-Boulder technology for thinner electronics commercialized by Kelvin Thermal of Boulder http://www.colorado.edu/news/releases/2015/02/17/cu-boulder-technology-thinner-electronicscommercialized-kelvin-thermal

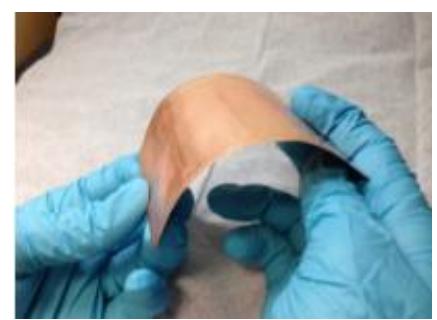

http://www.colorado.edu/news/releases/2015/02/17/cu-boulder-technology-thinner-electronics-commercialized-kelvin-thermal

\subsubsection{Massachusetts Institute of Technology: Sartorial Robotics}

Technology name: Sartorial Robotics project

Description: The Sartorial Robotics project intends to "enhance the social aspects of human-robotic interaction" by "merging fashion theory and robotics through the design and development of robotic systems. These systems facilitate interaction and play as well as mimic the materiality, aesthetics, and construction techniques of textiles, apparel, and fashion. This will enhance the social aspects of humanrobotic interaction and assist in how we situate robotics in our lives and cultures." One of the project's inventions includes the ZipperBot, which is "a small wearable robot capable of opening and closing zippers. When charged, the bot can scurry up and down and around contours." Developers suggest it may be "useful for certain labor uniforms like hazmat suits or spacesuits."

Status: Evolving

\section{Funding:}

Product link: http://robotic.media.mit.edu/portfolio/sartorial-robots/

Source: This tiny wearable robot can zip your jacket for you

http://www.theverge.com/2015/2/9/8005131/zipperbot-mit-wearable-zipper-robot-video

\subsubsection{McLaren Applied Technologies}

Technology name: Performance and health analytics

Description: McClaren and partners are creating technology and smart data systems that "give patients precise information about their bodies, and demonstrate which exercises and diets appear to work best for each of them." As opposed to just providing data, McClaren's technology provides additional timely insight into physiological signs.

Status: Evolving

\section{Funding:}


Product link: http://www.mclaren.com/appliedtechnologies/solutions/outputs

Source: McLaren to be a driving force in the wearable tech market http://www.telegraph.co.uk/sponsored/education/stem-awards/automotive/11434591/mclaren-appliedtechnologies-wearable-tech-plans.html

\subsubsection{Myovolt}

Technology name: Myovolt

Description: Myovolt is uses vibration to increase blood flow and help boost circulation. The user straps on the device and it delivers high intensity vibrations to muscle and soft tissue. It is a cloth strap (different sizes available for major muscles groups) accompanied with the Myovolt module. The device has an approximate 3 hour battery life and 70 minute continuous run time. Anticipated applications including helping to warm up muscles before training, increasing power and circulation, reducing injury risk, increasing circulation to remove lactic acid and provide a warm massage, as well as combining it with cold treatment to reduce swelling and speed recovery.

Status: Evolving

Funding: Crowdfunding

Product link: http://www.myovolt.com/\#!about/c13ps

Source: Kiwi firm Myovolt exports good vibrations http://www.stuff.co.nz/business/small-business/66689292/kiwi-firm-myovolt-exports-good-vibrations

\subsubsection{National Yang-Ming University}

Technology name: Wearable rehabilitation sensors

Description: This research explores "rehabilitation exercise assessment mechanism using three wearable sensors mounted on the chest, thigh and shank of the working leg in order to enable the patients with knee osteoarthritis to manage their own rehabilitation progress. In this work, time-domain, frequency-domain features and angle information of the motion sensor signals are used to classify the exercise type and identify whether their postures are proper or not." Researchers found that the system "can help patients self-manage their rehabilitation progress at home, and when the improper exercise posture is detected, an error alarm can be provided for the patients to verify their movements in real-time. Moreover, during the follow-ups at outpatient clinics or medical departments, the physicians can assess the patients' progress and how effectively the rehabilitation activities were carried out through the recording of the system."

Status: Evolving

Funding: Supported in part by grants from the National Science Council (MOST 103-2221-E-010-013MY2).

\section{Product link:}

Source: Wearable Sensor-Based Rehabilitation Exercise Assessment for Knee Osteoarthritis http://www.mdpi.com/1424-8220/15/2/4193 


\subsubsection{Neumitra}

Technology name: Brain health performance measuring

Description: Neumitra is developing technology that "measures the effects of stress on brain health performance in various ways, from wearable technology to tablet and mobile software and algorithms." Neumitra's app "helps users draw connections between stress and sleep, and how the two are impacted by life's daily demands." According to the company website, the company develops "embedded biomodules to accurately and continuously measure the autonomic nervous system throughout daily life demands. We use mobile software to link contextual data, such as events, locations, and activities, with the physiology of stress and sleep toward self-managing symptoms and identifying their causes."

Status: Evolving

Funding: Supported by MassChallenge

Product link: https://neumitra.com/

Source: Peter Thiel's philanthropic fund invests in brain health startup Neumitra http://www.bizjournals.com/boston/blog/startups/2015/02/peter-thiels-philanthropic-fund-invests-inbrain.html

\subsubsection{Pebble Technology}

Technology name: Wearable software and analytics

Description: Pebble, creator of the Pebble Watch smartwatch, is developing software to make use of wearable data, "focused on taking the information the hardware produces and turning it into something useful for the consumer."

Status: Evolving

Funding:

Product link: https://getpebble.com/

Source: Pebble CEO Migicovsky sees software as the key to wearables http://www.bizjournals.com/sanjose/news/2015/02/10/pebble-ceo-migicovsky-sees-software-as-the-keyto.html?page=all

\subsubsection{Shepherd Pathways: EyeRemember}

Technology name: EyeRemember

Description: EyeRemember is an app that runs on Google Glass and researchers are using it to gather feedback from patients with brain injuries, as well as their caregivers and therapists. The app "works in conjunction with Bluetooth low-energy beacons - small transmitters about the size of a car key fob - that must be worn or carried by friends, family, therapists and others in the user's community. The app uses the Bluetooth capabilities built into Glass to regularly scan for other beacons in the vicinity." The user, or 
user's caregiver, assigns a beacon to individuals (e.g., physicians, family member).Via Bluetooth, when "the beacon for an individual contact enters the vicinity of the Glass wearer, the beacon will be identified by the EyeRemember app. The contact information 'card' for that individual will appear automatically on Glass, showing a photo, name and relationship for the contact."

Status: Evolving

Funding: Received funding from Google's Glass Accessibility Award

\section{Product link:}

Source: Shepherd Center Researchers Testing Memory App for Google Glass and Wearable Technologies http://news.shepherd.org/shepherd-center-researchers-testing-memory-app-for-google-glass-andwearable-technologies/

\subsubsection{SUNU}

Technology name: SUNU sonar wristband

Description: SUNU is a sonar-equipped wristband designed to help visually impaired users perceive their environment and avoid obstacles. The device uses sound waves and gentle vibrations to guide a user. SUNU "locates objects 360 degrees around the wearer, delivering a mild or stronger buzz, depending on the distance and density of the obstacle. The band completes the picture of environmental conditions better than the typical white cane or guide dog alone - and is designed to work with both, not replace them."

Status: Evolving

Funding: Received $\$ 50,000$ prize at MassChallenge and the $\$ 25,000$ Perkins Assisted Technology sidecar prize from the Perkins School for the Blind.

Product link: http://sunu.io/index.php

Source: SUNU wearable for the blind navigates post-accelerator growth http://founderswire.com/2015/02/27/sunu-wearable-for-the-blind-navigates-post-accelerator-growth/

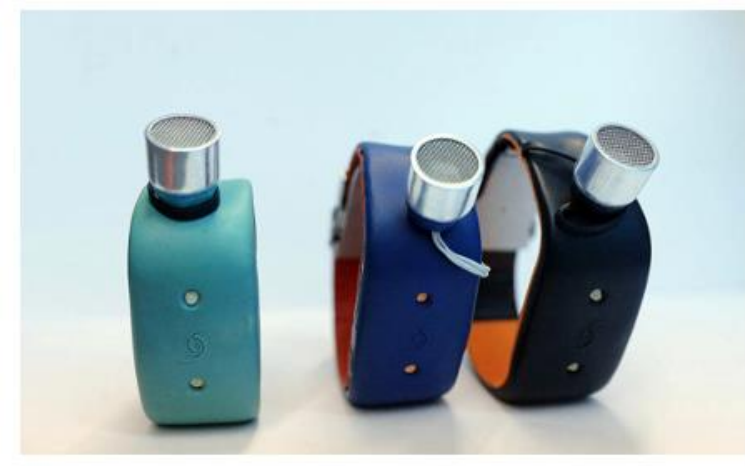

The SUNU band, wearable tech for the visually impaired, uses sonar to help identify and avoid dangerous obstacles.

Photo Source: http://founderswire.com/2015/02/27/sunu-wearable-for-the-blind-navigates-post-accelerator-growth/ 


\subsubsection{Terje Norderhaug (individual): Airport Al}

\section{Technology name: Airport AI}

Description: The Airport AI app "allows travelers at the airport to 'leave trails' and share their experience with fellow travelers thus providing updated airport traffic information. The app was designed "to more intelligently navigate places like the San Francisco International Airport. The app tracks fellow travelers as they move around, rewarding them with free air miles for sharing issues such as long waiting times or closed bathrooms. It's a bit like Waze for airports, or more generally, finding your way around on foot. There is also a web-based administrative dashboard, providing a live map showing the flow of people and their feedback." While the app was intended for travelers, "the concept can be generalized to any complex pedestrian/indoor situation. The use case is large buildings with many people trying to figure out where to go and what to do, benefiting from crowdsourcing the discovery and decision making." The app employs the indoo.rs software development kit that features mapping, routing, and analytics capabilities.

Status: Available

\section{Funding:}

Product link: http://airport-ai-enhancer.software.informer.com/2.0/

Source: Wearable Hackathon: The Connected Airport - Insights http://indoo.rs/wearable-hackathon-the-connected-airport-insights/

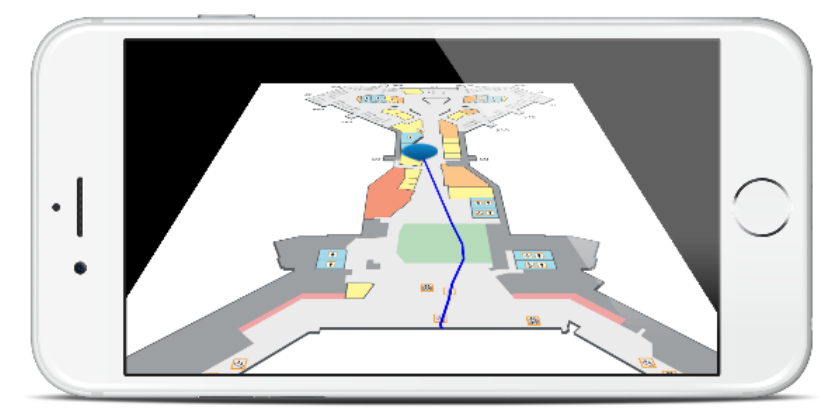

Photo Source: http://indoo.rs/wearable-hackathon-the-connected-airport-insights/

\subsubsection{Toshiba}

Technology name: TZ1031MBG and TZ1011MBG application processors, ApP Lite Internet of Things processor

Description: Toshiba is developing "range of sensor-laden processors designed to push wearables further through extended applications and long battery life." The processors offer "small form factor of the processors will enable wearable devices to also reduce in size, and are designed for low power performance." The TZ1031MBG and TZ1011MBG application processor package "integrates sensors for data collecting, is able to process data, includes flash memory for data storage and a Bluetooth controller for data transmission. The new processors are equipped with the same capabilities but expand functionality through a gyroscope added to the TZ1031MBG and a gyroscope and magnetometer to the TZ1011MBG." Toshiba is expanding its Internet of Things processors to be applied to measuring biomedical signals, pulse, ECG, etc. 
Status: Evolving - anticipated mass production in May 2015

\section{Funding:}

\section{Product link:}

Source: Toshiba updates range of wearable, Internet of Things processors http://www.zdnet.com/article/toshiba-updates-range-of-wearable-internet-of-things-processors/

\subsubsection{UL Technologies}

Technology name: Compliance services

Description: UL technologies launched "a comprehensive service that offers customized product validation, advisory, testing, risk mitigation, interoperability, and global market access services for wearable technology products. The services will help to assist manufacturers in supplying consumers with safer and more reliable wearable products while reducing the time to market." The services address the issue that "user safety is paramount for wearable technology products as they are worn for a prolonged period in direct contact with the human skin and rely on wireless technologies to transmit and receive personal information.

Status: Available

\section{Funding:}

Product link: http://industries.ul.com/blog/testing-solutions-for-wearable-technologies

Source: UL launched compliance services for the wearable technology industry http://www.householdappliancesworld.com/2015/02/11/ul-launched-compliance-services-for-thewearable-technology-industry/

\subsubsection{Vivametrica}

Technology name: Vivametrica health monitoring platform

Description: Developers with Vivametrica, a data analytics company, recognized "a relationship between physical activity data monitoring and health status" and developed a platform that can "be used by the consumer for health management." The platform is targeted at "insurance providers, health care providers and employee health and wellness programs" with algorithms and analytics that can be used "for research purposes, or to provide extra services such as additional data monitoring at a rehab clinic, for example. Health and wellness program providers can help companies quantify the effectiveness of their programs."

Status: Evolving

Funding: Seed funding

Product link: http://vivametrica.com/

Source: Vivametrica Powering the Evolution of 'Wearable Wellness' 


\subsubsection{Wicab: BrainPort}

Technology name: BrainPort

Description: BrainPort "converts video signals to electronic pulses that are felt on the tongue" to help visually impaired users interpret things in their environment. The device features a small video camera mounted to sunglasses connected via an electrical cord to a mouthpiece with a grid of 400 electrodes. The digital information from the video is translated into electrical stimulated bubble-like patterns on the tongue that represent shape, size, location, and motion of things in their environment. The Wicab website describes the feedback as "like a 400 point refreshable Braille display from which you learn to interpret the bubble-like patterns on their tongue as representative of objects in their surroundings."

Status: Evolving

Funding: Various sources including "funding in 2010 from two high-profile sources to pursue its new plan. One was the U.S. Department of Defense, which awarded Wicab a $\$ 3.2$ million grant to see if the technology could help soldiers blinded by improvised explosive devices in Iraq and Afghanistan. The other source was Google, which gave Wicab \$2.5 million to fund the 75-person study." Haiyin Capital, a Chinese venture capital firm, also invested $\$ 3$ million in Wicab.

Product link: http://www.wicab.com/en_us/

Source: Wicab's Wearable Vision Device Nears U.S. Market, Thanks to Google http://www.xconomy.com/wisconsin/2015/02/09/wicabs-wearable-vision-device-nears-u-s-market$\underline{\text { thanks-to-google/?single page }=\text { true }}$

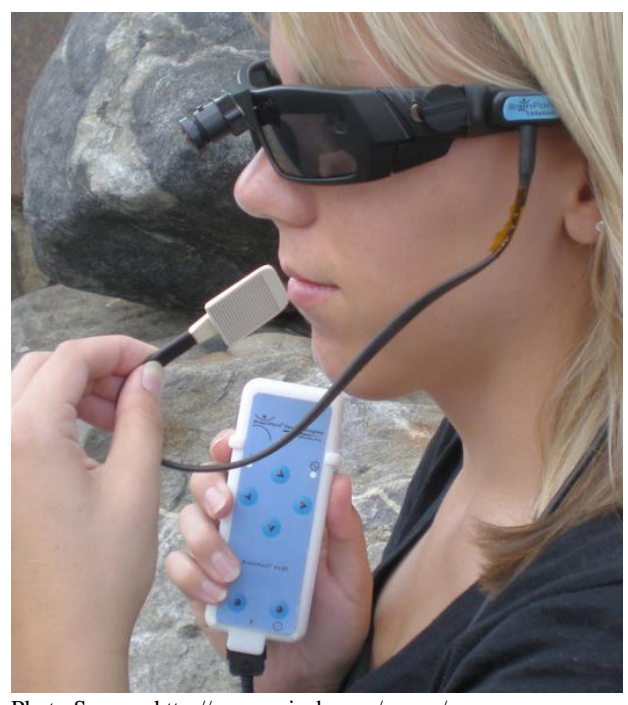

Photo Source: http://www.wicab.com/en_us/

\subsubsection{Xsens: MVN Biomech}

Technology name: MVN Biomech 
Description: MVN Biomech "transforms 3D human motion tracking into a wearable technology that can be used on production lines, sports fields, in vehicles and aircraft, in the home or any location where human body movement needs to be analyzed with high accuracy." The device has proposed applications in "ergonomics and human machine interaction (HMI), biomechanical analysis, rehabilitation, wearables development and sports science." The device is available as "full-body suit or a strap-based system. It is intuitive and can be set up for use anywhere, within minutes. Based on lightweight, wearable inertial sensors, MVN Biomech is highly portable, fitting into an average-sized backpack." The device allows users to visualize motion patterns: "the system channels wireless sensor data through biomechanical models and sensor fusion algorithms before visualizing them in real-time in Xsens' own MVN Studio Biomech software or in application-specific packages."

Status: Available

\section{Funding:}

Product link: https://www.xsens.com/products/mvn-biomech/

Source: Xsens transforms 3D human motion capture into wearable technology http://www.pandct.com/media/shownews.asp?ID=42779 
PNNL RTA Monthly Report Appendix A: Technology Summary

\section{Appendix A}

\section{Technology Summary}


PNNL RTA Monthly Report Appendix A: Technology Summary

\section{Appendix A}

\section{Technology Summary}

The following spreadsheet provides a summary of the technologies compiled in this report. For an electronic copy, please contact Jaki Upton at jaki.upton@pnnl.gov. This information is not meant to be an exhaustive list nor an endorsement of any technology described herein. 
PNNL RTA Monthly Report Appendix A: Technology Summary

\begin{tabular}{|c|c|c|c|}
\hline Company & Technology & Description & Status \\
\hline \multicolumn{4}{|c|}{ Sensor } \\
\hline \multicolumn{4}{|c|}{ Physiological } \\
\hline 270 Vision Ltd & BPM Physio fitness tracker & $\begin{array}{l}\text { Uses numerous embedded sensors to collect data that gets analyzed by } \\
\text { accompanying software. Once the analysis is done, the software uses the collected } \\
\text { data to create a visual representation that allows for easy comparison between } \\
\text { present and past data. }\end{array}$ & Available \\
\hline $\begin{array}{l}\text { Cambridge } \\
\text { Consultants }\end{array}$ & $\underline{\text { Xelflex }}$ & $\begin{array}{l}\text { Smart garment fitted with fiber-optic sensors and low-cost impulse radar to measure } \\
\text { body motion, partnered with algorithms that translate data into feedback and } \\
\text { coaching on posture, movement, etc. Features } 24 \text {-hour battery life. }\end{array}$ & Evolving \\
\hline $\begin{array}{l}\text { Center for Sustainable } \\
\text { Health }\end{array}$ & Project HoneyBee & $\begin{array}{l}\text { Model for collecting and validating data to sustain human health using data gathered } \\
\text { from biosensors. CSH is performing observational clinical trials to test the utility of } \\
\text { commercial wearable devices for monitoring patients. }\end{array}$ & Evolving \\
\hline $\begin{array}{l}\text { Chinese Academy of } \\
\text { Sciences }\end{array}$ & $\begin{array}{l}\text { Wearable temperature } \\
\text { sensor using graphene } \\
\underline{\text { nanowalls }}\end{array}$ & $\begin{array}{l}\text { Wearable temperature sensor using graphene nanowalls to monitor body } \\
\text { temperature in real time and present response/recovery speed as well as long-term } \\
\text { stability, }\end{array}$ & Evolving \\
\hline $\begin{array}{l}\text { Florida International } \\
\text { University in Miami and } \\
\text { North Carolina State } \\
\text { University }\end{array}$ & $\begin{array}{l}\text { Wearable cortisol monitoring } \\
\text { strip }\end{array}$ & $\begin{array}{l}\text { Tiny wearable sensor strip to measure the hormone cortisol, which signals stress, as } \\
\text { well as to track sleep and alert doctors when a person is dangerously tense. The } \\
\text { strip records levels over time, creating a profile for a user to monitor their stress } \\
\text { levels across various activities }\end{array}$ & Evolving \\
\hline Hexoskin & Biometric Shirt & $\begin{array}{l}\text { Shirt features two conductive bands that measure and interpret performance data for } \\
\text { a user, including heart rate recovery, lung capacity, and other signals that the user } \\
\text { can monitor via an appl. The device features a 14-hour battery life and can store up } \\
\text { to } 150 \text { hours of data. }\end{array}$ & Available \\
\hline Movement Interactive & $\underline{\text { Hiji Band }}$ & $\begin{array}{l}\text { Adjustable headband that detects and reports traumatic brain injury in sports players } \\
\text { or other users. Activity related to brain injury is reported to a mobile app and can be } \\
\text { gathered and analyzed long-term. Easily comprehensible text, graphs, and images } \\
\text { are used by the software to send the data to the users }\end{array}$ & Evolving \\
\hline
\end{tabular}


PNNL RTA Monthly Report

Appendix A: Technology Summary

\begin{tabular}{|c|c|c|c|}
\hline i1 Biometrics & $\underline{\text { Impact Intelligence System }}$ & $\begin{array}{l}\text { Vector Mouthguard with ESP } \mathrm{TM} \text { Chip Technology to gather and analyze intracranial } \\
\text { impact data and provide real-time objective qualitative and quanitative information. } \\
\text { The system comprises offers an accelerometer and gyroscope technology } \\
\text { embedded on a microscopic circuit board, sideline assessment application, real-time } \\
\text { wireless base station, customizable software package, mobile notification device, } \\
\text { mouthguard charging stations, and a field kit case. }\end{array}$ & Evolving \\
\hline $\begin{array}{l}\text { Kofi Odame } \\
\text { (Individual) }\end{array}$ & $\begin{array}{l}\text { Wearable asthma- } \\
\text { monitoring device }\end{array}$ & $\begin{array}{l}\text { Wearable, low-energy consuming asthma-monitoring device that sticks to a patient's } \\
\text { chest, records their breathing sounds, and if it detects an anomaly it will send } \\
\text { notifications to the user's smartphone if they need to make changes to their self- } \\
\text { management plan or take medication. }\end{array}$ & Evolving \\
\hline $\begin{array}{l}\text { Medidata, Garmin } \\
\text { International Inc. }\end{array}$ & $\begin{array}{l}\text { Mobile health technology for } \\
\underline{\text { clinical trials }}\end{array}$ & $\begin{array}{l}\text { Integrates Garmin's vívofit activity tracker with the Medidata Clinical Cloud® } \\
\text { Medidata and the use of mobile health (mHealth) devices to measure patient data } \\
\text { (steps taken, distance, calories burned and hours slept) and integrate it with other } \\
\text { clinical data. }\end{array}$ & Evolving \\
\hline $\begin{array}{l}\text { Scripps Translational } \\
\text { Science Institute }\end{array}$ & $\begin{array}{l}\text { Sensor Technology and } \\
\text { Analytics to Monitor, Predict } \\
\text { and Protect Ebola Patients } \\
\text { (STAMP2) }\end{array}$ & $\begin{array}{l}\text { Wireless device to screen for Ebola case. Sensors applied like a Band-Aid monitor a } \\
\text { patient's vital signs (heart rate, respiratory rate, temperature, and oxygen saturation) } \\
\text { and data from the monitors is transmitted to PhyslQ's analytics platform, which uses } \\
\text { next-generation algorithms to detect changes in patients over time. }\end{array}$ & Evolving \\
\hline Spectros & $\underline{\text { T-Stat }^{\circledR}, \text { Bodysigns }^{\circledR}}$ & $\begin{array}{l}\text { T-Stat is a tissue oximeter that detects an insufficient supply of oxygen to tissue. } \\
\text { BodySigns is a loose-fit heart rate monitor that uses white light to produce medical- } \\
\text { grade data. }\end{array}$ & Available \\
\hline Stryd & $\underline{\text { Stryd wearable power meter }}$ & $\begin{array}{l}\text { Sensing technology that calculates run power measured in watts and uses } \\
\text { algorithms to calculate force and velocity. Features a battery life of longer than a } \\
\text { year and helps a user understand their performance and establish baseline data. }\end{array}$ & Evolving \\
\hline University of Tokyo & $\underline{\text { Wearable fever alarmband }}$ & $\begin{array}{l}\text { Wearable, flexible, and self-powered fever alarmband sounds an alarm in the case } \\
\text { of high body temperature. }\end{array}$ & Evolving \\
\hline Vital Connect & $\underline{\text { HealthPatch MD }}$ & $\begin{array}{l}\text { Small, thin wearable device that monitors a number of biometric signals, providing } \\
\text { medical professionals with the ability to remotely monitor patients' respiratory and } \\
\text { cardiac data, body movement, temperature, and other such health indicators. The } \\
\text { data is transferred via BlueTooth } 4.0 \text {, and can be interpreted and analyzed using } \\
\text { Vital Connect's custom-designed software }\end{array}$ & Evolving \\
\hline X2 Biosystems & $\begin{array}{l}\text { Integrated Concussion } \\
\text { Evaluation }\end{array}$ & $\begin{array}{l}\text { Cloud-based application that combines wearable biometric sensors and mobile } \\
\text { software to spot, monitor, and enable response to traumatic brain injury. }\end{array}$ & Evolving \\
\hline Zhejiang University & $\underline{\text { Wearable sensor systems for }}$ & $\begin{array}{l}\text { Research exploring development of and fusion of wearable sensing technologies, } \\
\text { wireless communication techniques and a low energy-consumption microprocessor } \\
\text { with high performance data processing algorithms for the continuous health status } \\
\text { monitoring of infants. }\end{array}$ & Evolving \\
\hline \multicolumn{4}{|c|}{ Biological } \\
\hline
\end{tabular}


PNNL RTA Monthly Report Appendix A: Technology Summary

\begin{tabular}{|c|c|c|c|}
\hline $\begin{array}{l}\text { Edgewood Chemical } \\
\text { Biological Center }\end{array}$ & VOCkit System & $\begin{array}{l}\text { Postage stamp-sized colorimetric detection assay printed with a grid of several } \\
\text { dozen indicator chemicals that detect and differentiate chemical and biological } \\
\text { hazards and transmit results to the higher command. }\end{array}$ & Evolving \\
\hline \multicolumn{4}{|c|}{ Other } \\
\hline $\begin{array}{l}\text { Infineon Technologies } \\
\text { AG }\end{array}$ & $\begin{array}{l}\text { DPS310 Micro Electro } \\
\text { Mechanical System (MEMS) }\end{array}$ & $\begin{array}{l}\text { Miniature barometric air pressure and temperature sensor. The device provides } \\
\text { accuracy, even pressures from } 300 \mathrm{hPa} \text { to } 1200 \mathrm{hPa} \text { and at temperatures from }-40^{\circ} \mathrm{C} \\
\text { to } 85^{\circ} \mathrm{C} \text {. }\end{array}$ & $\begin{array}{l}\text { Soon to be } \\
\text { released }\end{array}$ \\
\hline $\begin{array}{l}\text { Institute for Integrative } \\
\text { Nanosciences }\end{array}$ & Magnetic field sensor & $\begin{array}{l}\text { Sensor that allows users to detect magnetic fields via an electronic skin with a } \\
\text { magneto-sensory system that equips the recipient with a 'sixth sense' able to } \\
\text { perceive the presence of static or dynamic magnetic fields. }\end{array}$ & Evolving \\
\hline STMicroelectronics & $\begin{array}{l}\text { UVIS25 ultraviolet radiation } \\
\text { sensor }\end{array}$ & $\begin{array}{l}\text { Sensor device that comprises a digital ultra-compact UV sensor aimed at all UV- } \\
\text { sensing markets, including wearable devices, smartphone and tablet apps, and } \\
\text { weather-station equipment. UVIS25 calculates the UVI internally, uniquely } \\
\text { eliminating the need for external processing algorithms or calibration. }\end{array}$ & $\begin{array}{l}\text { Soon to be } \\
\text { released }\end{array}$ \\
\hline $\begin{array}{l}\text { Universidad } \\
\text { Politécnica de Madrid } \\
\text { Institute of } \\
\text { Optoelectronics } \\
\text { Systems and } \\
\text { Microtechnology }\end{array}$ & Flexible nanosensors & $\begin{array}{l}\text { Optical nanosensors using low-cost materials and capable of sticking on uneven } \\
\text { surfaces and biological surfaces like human skin to measure refractive index } \\
\text { variations of the surrounding medium and this can be used to detect chemical } \\
\text { substances }\end{array}$ & Evolving \\
\hline $\begin{array}{l}\text { Yonsei University and } \\
\text { Stanford University }\end{array}$ & $\begin{array}{l}\text { Conductive Fiber-Based } \\
\text { Ultrasensitive Textile } \\
\text { Pressure Sensor }\end{array}$ & $\begin{array}{l}\text { Highly conductive fibers coated with dielectric rubber materials to develop a flexible } \\
\text { and sensitive textile-based pressure sensor that can be applied to make smart } \\
\text { gloves and clothes which can control machines wirelessly as human-machine } \\
\text { interfaces. }\end{array}$ & Evolving \\
\hline \multicolumn{4}{|c|}{ Displays } \\
\hline \multicolumn{4}{|c|}{ Heads-Up Displays } \\
\hline Apple & $\begin{array}{l}\text { Head-Mounted Display } \\
\text { Apparatus for Retaining a } \\
\text { Portable Electronic Device } \\
\text { with Display }\end{array}$ & $\begin{array}{l}\text { Head-mounted display apparatus for retaining a portable electronic device with } \\
\text { display with a slot for inserting an iPhone. The proposed device uses the } \\
\text { smartphone screen as the display and offers a hand-held remote control. }\end{array}$ & Evolving \\
\hline Apple & Presentation device & $\begin{array}{l}\text { Device for controlling operations of a portable presentation device to be worn by a } \\
\text { user and that is capable of presenting media content to the user such as earphones, } \\
\text { headphones, goggles or faceplates with video/audio capabilities }\end{array}$ & Evolving \\
\hline BMW & $\underline{\text { Virtual reality goggles }}$ & $\begin{array}{l}\text { Virtual reality goggles that share information on a lens to improve safety and driving } \\
\text { experiences. Speed data will be collected, and car sharing and travel update alerts } \\
\text { will be projected onto the screen. }\end{array}$ & Evolving \\
\hline
\end{tabular}


PNNL RTA Monthly Report Appendix A: Technology Summary

\begin{tabular}{|c|c|c|c|}
\hline DAQRI & $\begin{array}{l}\text { Melon headband and DAQRI } \\
\underline{\text { Smart Helmet }}\end{array}$ & $\begin{array}{l}\text { Integrating Melon's electroencephalogram (electrical activity in the brain) tracking } \\
\text { headband into DAQRI's Smart Helmet, part of DAQRI's 4D work to develop } \\
\text { technology that projects data on a user's environment. }\end{array}$ & Evolving \\
\hline Google & $\underline{\text { Google Glass }}$ & $\begin{array}{l}\text { Google Glass is being used by the Amsterdam's Schiphol's airport authority officers } \\
\text { as a hands-free way to look up gate and airplane information and to test Google's } \\
\text { face computer on travelers passing through the terminal to understand customers' } \\
\text { experiences. }\end{array}$ & Available \\
\hline Kopin & $\underline{\text { Nanojet }}$ & $\begin{array}{l}\text { The NanoJet process releases tiny drops of liquid crystal material with greater } \\
\text { precision (variation within a few nano grams) and provides for a purer, better } \\
\text { controlled and very uniform layering of the liquid crystal material in the fabrication of } \\
\text { displays, resulting in superior image quality and higher brightness. }\end{array}$ & Evolving \\
\hline $\begin{array}{l}\text { University Bremen, } \\
\text { Friedrich Wilhelm } \\
\text { Bessel Institute } \\
\text { gGmbH }\end{array}$ & $\begin{array}{l}\text { Hybrid brain-computer } \\
\text { interface headset }\end{array}$ & $\begin{array}{l}\text { This hybrid brain-computer interface headset comprises a hard case cap with } 22 \\
\text { EEG electrode positions (a) two eye cameras, one camera for observation of the } \\
\text { environment and four steady-state visual evoked potential-stimuli at the edges of the } \\
\text { infrared mirrors. }\end{array}$ & Evolving \\
\hline Sony & $\underline{\text { SmartEyeglass }}$ & $\begin{array}{l}\text { Internet-linked eyewear that superimposes information (text, symbols, images) onto } \\
\text { the user's field of view. The device features an accelerometer, gyroscope, electronic } \\
\text { compass, brightness sensor, microphones, Bluetooth, Android compatibility, 3M } \\
\text { pixel camera, VGA movie capability. }\end{array}$ & $\begin{array}{l}\text { Soon to be } \\
\text { released }\end{array}$ \\
\hline VitalMedicals & $\begin{array}{l}\frac{\text { VitalVideo, VitalCom, }}{\text { VitalStream smart glass }} \\
\underline{\text { technologies }}\end{array}$ & $\begin{array}{l}\text { VitalVideo streams live ultrasound, fluoroscopy, and endoscopy video to smart } \\
\text { glasses and tablets during procedures, bringing that data right into a surgeon's field } \\
\text { of view. VitalCom enables clinicians to talk with anyone else in the hospital with just } \\
\text { a voice command to their smart glasses or mobile device, as well as sharing their } \\
\text { point of view via smart glasses' front-facing camera. VitalStream streams live vital } \\
\text { signs and alarms to the anesthesiologist or circulating nurse's smart glasses or } \\
\text { tablet during conscious sedation procedures to improve situational awareness. }\end{array}$ & Evolving \\
\hline Vuzix, HeadApp & $\underline{\text { Glass4Flight }}$ & $\begin{array}{l}\text { Combines Vuzix glasses with Headapp to transform multimedia glasses into an } \\
\text { cockpit. The Glass4Flight application connects an integrated system known as WiFly } \\
\text { to pilots. With WiFly, pilots get immediate access to a host of real time data points } \\
\text { together in one handy package known as the Virtual Glass Cockpit. }\end{array}$ & Evolving \\
\hline \multicolumn{4}{|c|}{ Power } \\
\hline \multicolumn{4}{|c|}{ Self-Powering (Harvesters) } \\
\hline $\begin{array}{l}\text { Chinese Academy of } \\
\text { Sciences }\end{array}$ & $\begin{array}{l}\text { Hybridized Electromagnetic } \\
\underline{\text { Triboelectric Nanogenerator }}\end{array}$ & $\begin{array}{l}\text { Research exploring hybridized electromagnetic triboelectric nanogenerator for highly } \\
\text { efficient scavenging of biomechanical energy to sustainably power wearable } \\
\text { electronics by human walking. Researchers integrated the hybridized nanogenerator } \\
\text { into a commercial shoe "to harvest biomechanical energy induced by human walking } \\
\text { to directly light up tens of light-emitting diodes in the shoe and sustainably power a } \\
\text { smart pedometer for reading the data of a walking step, distance, and energy } \\
\text { consumption. }\end{array}$ & Evolving \\
\hline
\end{tabular}


PNNL RTA Monthly Report Appendix A: Technology Summary

\begin{tabular}{|c|c|c|c|}
\hline $\begin{array}{l}\text { HSG-IMIT Institute of } \\
\text { Micromachining and } \\
\text { Information } \\
\text { Technology }\end{array}$ & Energy-producing shoe & $\begin{array}{l}\text { A 'shock harvester' that capitalizes on the force of the heel hitting the ground, while } \\
\text { the 'swing harvester' produces power by monopolizing the force generated while the } \\
\text { leg is in motion. }\end{array}$ & \\
\hline \multicolumn{4}{|c|}{ Power Supplies } \\
\hline Ballard Power Systems & Fuel cell technology & $\begin{array}{l}\text { Fuel cell technology is being applied to develop a wearable fuel cell power system } \\
\text { for soldiers and applied to the automotive industry, anticipated to provide similar or } \\
\text { better performance than current wearable lithium-ion batteries while decreasing } \\
\text { weight and volume by more than } 50 \% \text { for } 72 \text {-hour missions. }\end{array}$ & Evolving \\
\hline $\begin{array}{l}\text { Sungkyunkwan } \\
\text { University }\end{array}$ & $\begin{array}{l}\text { Nanopatterned Textile-Based } \\
\text { Wearable Triboelectric } \\
\text { Nanogenerator }\end{array}$ & $\begin{array}{l}\text { Researchers are exploring fully flexible, foldable nanopatterned wearable } \\
\text { triboelectric nanogenerator with high power-generating performance and mechanical } \\
\text { robustness. Researchers demonstrated the technology to power of LEDs, the LCD, } \\
\text { and the keyless vehicle entry system. }\end{array}$ & Evolving \\
\hline \multicolumn{4}{|c|}{ Communications } \\
\hline \multicolumn{4}{|c|}{ Short-range, low-power Bluetooth } \\
\hline $\begin{array}{l}\text { Automated Assembly } \\
\text { Corporation }\end{array}$ & $\frac{\text { InfoSkin near-field }}{\text { communications (NFC) }}$ & $\begin{array}{l}\text { Near-field communications tags that adhere to the skin or other surfaces and employ } \\
\text { Automated Assembly's patent-pending wire write technology that uses copper wire } \\
\text { rather than a flexible etched circuit to be flexible, comfortable, and green with } \\
\text { improved NFC range and improved ability to be read at different angles. }\end{array}$ & Evolving \\
\hline FreeWavz & $\begin{array}{l}\text { FreeWavz wireless smart } \\
\text { earphones }\end{array}$ & $\begin{array}{l}\text { Wireless smart earphones with the capability to measure heartrate and report and } \\
\text { provide audio alerts regarding calories burned, distance, and steps while also } \\
\text { playing music over Bluetooth, with the added capability of configurable listen- } \\
\text { through. }\end{array}$ & $\begin{array}{l}\text { Soon to be } \\
\text { released }\end{array}$ \\
\hline \multicolumn{4}{|c|}{ Hands-Free Operation } \\
\hline $\begin{array}{l}\text { RHL Vision } \\
\text { Technologies Pvt. } \\
\text { Ltd. }\end{array}$ & Fin thumb ring & $\begin{array}{l}\text { Connects with devices via Bluetooth and allows the user to control them by simply } \\
\text { moving the ringed finger on the palm. Different points on the palm serve as the } \\
\text { menu, keypad, or gesture space, providing options for smart phone, keypad, } \\
\text { reading, calendar, head-mounted display, and various other modes. }\end{array}$ & $\begin{array}{l}\text { Soon to be } \\
\text { released }\end{array}$ \\
\hline \multicolumn{4}{|c|}{ Cameras } \\
\hline Contour & ContourGPS & $\begin{array}{l}\text { Action video camera equipped with GPS technology to track location, speed and } \\
\text { altitude multiple times per second, while capturing high-definition video. The } \\
\text { lightweight ( } 4.3 \text { ounces) device shoots } 1080 \text { p video and features } 135 \text {-degree angle } \\
\text { lens, live streaming, still photo mode, and GPS video mapping that connects to } \\
\text { smart devices. }\end{array}$ & Available \\
\hline Digital Ally & Wearable cameras & $\begin{array}{l}\text { Digital Ally was awarded Government Service Administration status. Digital Ally } \\
\text { specializes in advanced digital video police cameras, fleet records and law } \\
\text { enforcement surveillance equipment, as well as sports cameras. Digital Ally also } \\
\text { filed a patent for breath analyzer system and computer program for preserving } \\
\text { breath analysis data. }\end{array}$ & Evolving \\
\hline
\end{tabular}


PNNL RTA Monthly Report Appendix A: Technology Summary

\begin{tabular}{|c|c|c|c|}
\hline First V1sion & First V1sion camera garment & $\begin{array}{l}\text { Camera-equipped t-shirt fitted with a small high-definition camera with an optical } \\
\text { lens and a sports jersey with biometric sensors throughout. The biometric sensors } \\
\text { gather information with an Intel Edison chip, allowing the shirt to send player data to } \\
\text { computers via WiFi. }\end{array}$ & Evolving \\
\hline Marantz & $\underline{\text { PMD-901V video recorder }}$ & $\begin{array}{l}\text { GPS-enabled, light-weight, durable, wearable video recording device that can } \\
\text { capture a full day's work. Features } 32 \mathrm{~GB} \text { of secure, tamper-proof internal storage, } \\
\text { the PMD-901V captures up to } 8 \text { continuous hours of full HD video at } 2304 \times 1296 \\
\text { resolution, rendering impeccable detail and clarity, in harsh conditions. Attaches to } \\
\text { the user's clothing with a swiveling clip for optimum video capture from the ultra-wide } \\
\text { 140-degree field-of-view lens. }\end{array}$ & $\begin{array}{l}\text { Soon to be } \\
\text { released }\end{array}$ \\
\hline MeMini & MeMini wearable camera & $\begin{array}{l}\text { Body-worn camera that constantly films and features special "recall" technology, as } \\
\text { well as } 1080 \mathrm{HD} \text { capability, } 140 \text {-degree field of view, } 30 \text { frames per second shooting, } \\
\text { Sony } 8 \text { megapixel image sensor, wifi and Bluetooth capability, and } 3.5 \text { hour battery } \\
\text { life. The device streams to a smartphone to set the recall time and review/manage } \\
\text { footage. }\end{array}$ & $\begin{array}{l}\text { Soon to be } \\
\text { released }\end{array}$ \\
\hline QindredCam & $\underline{\text { QindredCam }}$ & $\begin{array}{l}\text { Clip-on camera that shoots photo and video transmitted to the cloud. The device } \\
\text { features features weather-proof casing, noise-cancelling mic, interchangeable } \\
\text { magnet/clip options, wifi and Bluetooth capability, USB port, 4GB storage, and 10-15 } \\
\text { hour battery life. }\end{array}$ & Evolving \\
\hline Swann & $\begin{array}{l}\text { Bolt HD wearable action } \\
\text { camera }\end{array}$ & $\begin{array}{l}\text { Action camera the offers high definition video recording, } 12 \text { mega-pixel still camera, } \\
1.5 \text {-hour recording per charge, MicroSD, mounts, and remote control. }\end{array}$ & Available \\
\hline Vievu & $\underline{\text { Vievu cameras }}$ & $\begin{array}{l}\text { Wearable cameras providing real-time streaming, HD video, built-in wifi, pairing with } \\
\text { smartphone, military-grade anodized aluminum housing, and other capabilities. The } \\
\text { device offers } 16 \mathrm{~GB} \text { storage and can record for } 2.5 \text { hours or stream for } 90 \text { minutes on } \\
\text { a single charge. }\end{array}$ & Available \\
\hline \multicolumn{4}{|c|}{ Breathing Apparatus } \\
\hline Scott & $\begin{array}{l}\text { Self-contained breathing } \\
\text { apparatus }\end{array}$ & $\begin{array}{l}\text { Self-contained breathing apparatus equipped with Pak-Tracker that allows } \\
\text { for faster location of a downed firefighter. With the newly designed sweep } \\
\text { gauge, the user can easily monitor air supply. }\end{array}$ & Available \\
\hline \multicolumn{4}{|c|}{ Exoskeleton } \\
\hline Hiroshima University & Sensorimotor Enhancing Suit & $\begin{array}{l}\text { Muscle assistive equipment made of flexible fabrics that enhances sensorimotor } \\
\text { functions by reducing the muscle load of the upper limbs. }\end{array}$ & Evolving \\
\hline University of Bristol & $\underline{\text { Smart trousers }}$ & $\begin{array}{l}\text { Uses artificial muscles made from smart materials and reactive plastic-like } \\
\text { molecules capable of exerting great forces. Control systems will be incorporated that } \\
\text { monitor the wearer and work with the body's own muscles to provide assistance } \\
\text { when needed. }\end{array}$ & Evolving \\
\hline \multicolumn{4}{|c|}{ Wearable Computers } \\
\hline
\end{tabular}


PNNL RTA Monthly Report Appendix A: Technology Summary

\begin{tabular}{|c|c|c|c|}
\hline Blu & Blu wearable smartphone & $\begin{array}{l}\text { Flexible, wearable smart phone, utilizing a flexible organic light emitting display } \\
\text { (OLED), overlapping clasp, light bar on each side of the wristband, } 5 \times 2 \text { inch display, } \\
\text { speakers for } 360 \text { degrees of sound, Gesture Orientation User Interface, and } \\
\text { wireless capability. The device is equipped with a wireless dock for recharging and } \\
\text { file transfer via wireless power transmission and near-field communication adaptable } \\
\text { via USB to PC or power outlet. }\end{array}$ & Evolving \\
\hline Neptune & $\underline{\text { Duo wearable computer }}$ & $\begin{array}{l}\text { The Hub, a bangle style wearable computer, allows users to make calls and text } \\
\text { messages, check into various social networking sites, track fitness data, and more } \\
\text { from their wrist. The companion 'Pocket' screen, which looks like a smartphone, acts } \\
\text { as a keyboard, track pad or monitor. }\end{array}$ & Evolving \\
\hline Samsung & Orbis smartwatch & $\begin{array}{l}\text { Smartwatch with a round metal case device, which rotating bezel to the left will help } \\
\text { you to explore the notification center and identify that you are searching for, and } \\
\text { rotating the bezel to the right will reject a call from your smartphone. }\end{array}$ & Evolving \\
\hline \multicolumn{4}{|c|}{ Other } \\
\hline $\begin{array}{l}\text { Avon Protection, } \\
\text { SecureBio, Ltd. }\end{array}$ & $\begin{array}{l}\text { Personal protective } \\
\text { equipment with } \mathrm{NH} 15 \\
\text { escape hood }\end{array}$ & $\begin{array}{l}\text { Personal protective equipment designed to address chemical, biological, radiological } \\
\text { and nuclear threats and features Avon's NH15 hood, which is an NIOSH certified } \\
\text { CBRN Air Purifying Escape Respirator. Offers respiratory protection, suits, gloves } \\
\text { and personal decontamination solutions, and biological and explosives detection. }\end{array}$ & Evolving \\
\hline Boogio & $\begin{array}{l}\text { Boogio footwear pressure } \\
\underline{\text { sensors }}\end{array}$ & $\begin{array}{l}\text { Sticker placed underneath an insole that has pressure sensors across toe heel and } \\
\text { arch, with } 65,000 \text { layers of pressure sensitivity. A small device clips to the side of the } \\
\text { shoe and contains a gyroscope, 3D accelerometer, Bluetooth connectivity, and } \\
\text { battery. }\end{array}$ & Evolving \\
\hline Broadcom & Smartwatch platform & $\begin{array}{l}\text { Smartwatch platform that reduces power consumption by up to } 40 \% \text { (over the } \\
\text { previous generation) for Android Wear devices. It features system-on-a-chip, wifi } \\
\text { and Bluetooth connectivity, NFC, and wireless charging. The platform offers smaller } \\
\text { form factor, enabling original equipment manufacturers to add more features or } \\
\text { include a larger battery. }\end{array}$ & Evolving \\
\hline Dainese & D-Air Ski wearable airbag & $\begin{array}{l}\text { Wearable airbag for skiing. The vest uses internal sensors including gyroscopes, } \\
\text { accelerometers, and a GPS system to sense when a skier is toppling, deploying the } \\
\text { airbag if speed and angle suddenly change. The design is relatively lightweight, } \\
\text { powered by a rechargeable lithium-ion battery, made of materials similar to } \\
\text { moisture-wicking shirts, features an onboard computer about the size of a credit } \\
\text { card. }\end{array}$ & Evolving \\
\hline
\end{tabular}


PNNL RTA Monthly Report Appendix A: Technology Summary

\begin{tabular}{|c|c|c|c|}
\hline Eccrine Systems & $\begin{array}{l}\text { Sweatronics }{ }^{\mathrm{TM}} \text { disposable } \\
\underline{\text { sweat-monitoring device }}\end{array}$ & $\begin{array}{l}\text { Disposable sweat-monitoring device that tests sweat and transmit results wirelessly } \\
\text { into the cloud. The Band-Aid-sized Sweatronics } \text { TM }^{\mathrm{M}} \text { platform is a modular, flexible } \\
\text { system capable of measuring multiple different analytes in sweat and wirelessly } \\
\text { transmitting data via a transceiver to remote applications. The device features } \\
\text { radiofrequencing identification and Bluetooth capabilities, as well as a software } \\
\text { development kit to interface with a range of devices. }\end{array}$ & Evolving \\
\hline Heddoko & $\underline{\text { Heddoko smart garment }}$ & $\begin{array}{l}\text { Tracks movement in 3D and provides users visual feedback and analysis via an app. } \\
\text { Sensors in the fabric measure arms, legs, chest, back, and stomach and can provide } \\
\text { real-time feedback and statistical performance analysis. }\end{array}$ & Evolving \\
\hline iGel & iGel full-body airbag suit & $\begin{array}{l}\text { Hedgehog-inspired fullbody airbag that uses a series of microelectromechanical } \\
\text { system of smart sensors to detect crash-level forces and automatically inflate around } \\
\text { the wearer. }\end{array}$ & Evolving \\
\hline Immersion Corporation & Instinctive Alerts Framework & $\begin{array}{l}\text { Scalable solution for designing a wearable device that effectively and privately } \\
\text { communicates to users through tactile effects, without requiring any additional audio } \\
\text { or visual context. The framework's tactile effects are designed to intuitively direct } \\
\text { user response from the first use and provide a natural learning curve for } \\
\text { understanding the specific meaning of the alerts over time. }\end{array}$ & Evolving \\
\hline Intel & $\begin{array}{l}\text { RealSense environmental } \\
\underline{\text { sensing system }}\end{array}$ & $\begin{array}{l}\text { Designed for visually impaired users with a camera and six sensors attached to } \\
\text { various points of a jacket. As objects or people approach the wearer, the sensors on } \\
\text { the shirt detect the distance and direction of the object and vibrate, giving the } \\
\text { wearer a sense of their immediate environment and letting them take necessary } \\
\text { action. }\end{array}$ & Evolving \\
\hline JOT Automation & $\begin{array}{l}\text { JOTG3 smartphone testing } \\
\text { platform }\end{array}$ & $\begin{array}{l}\text { Smartphone testing system that allows users to run tests on radio frequency } \\
\text { material, as well as electrical systems, mechanical systems, touchscreen and } \\
\text { buttons, audio, and even plug-in connections to help make sure everything works } \\
\text { according to Hoyle, so to speak, before getting released to market. }\end{array}$ & Evolving \\
\hline Hanyang University & $\underline{\text { Multiferroric materials }}$ & $\begin{array}{l}\text { Bendable devices by manufacturing a thin film that keeps its useful electric and } \\
\text { magnetic properties even when highly curved. Researchers propose that flexible } \\
\text { multiferrorics could enable new wearable devices such as health monitoring } \\
\text { equipment or virtual reality attire as well as use in high-density, energy efficient } \\
\text { memory and switches in such devices. }\end{array}$ & Evolving \\
\hline Hitachi & $\underline{\text { Happy-measuring wearable }}$ & $\begin{array}{l}\text { A card-size device equipped with an acceleration sensor that monitors a group's } \\
\text { behavior and sends data to cloud-based servers. The card collects data } 50 \text { times a } \\
\text { second and detects certain types of actions from various types of movement such as } \\
\text { walking, nodding and typing. It then uses the data it has collected to interpret the } \\
\text { group's overall mood. Hitachi reports the service will be available on a subscription } \\
\text { basis with an annual fee. }\end{array}$ & Evolving \\
\hline $\begin{array}{l}\text { Kelvin Thermal } \\
\text { Technologies, } \\
\text { University of Colorado }\end{array}$ & $\begin{array}{l}\text { Thermal management } \\
\text { technologies }\end{array}$ & $\begin{array}{l}\text { an ultra-thin, flexible thermal heat-transfer device that can be mounted on electronic } \\
\text { devices }\end{array}$ & Evolving \\
\hline
\end{tabular}


PNNL RTA Monthly Report

Appendix A: Technology Summary

\begin{tabular}{|c|c|c|c|}
\hline $\begin{array}{l}\text { Massachusetts } \\
\text { Institute of Technology }\end{array}$ & $\underline{\text { Sartorial Robotics project }}$ & $\begin{array}{l}\text { Merging fashion theory and robotics through the design and development of robotic } \\
\text { systems. These systems facilitate interaction and play as well as mimic the } \\
\text { materiality, aesthetics, and construction techniques of textiles, apparel, and fashion. } \\
\text { Inventions include ZipperBot, for example, which is a small wearable robot capable } \\
\text { of opening and closing zippers. }\end{array}$ & Evolving \\
\hline $\begin{array}{l}\text { McLaren Applied } \\
\text { Technologies }\end{array}$ & $\begin{array}{l}\text { Performance and health } \\
\underline{\text { analytics }}\end{array}$ & $\begin{array}{l}\text { Technology and smart data systems that provides additional timely insight into } \\
\text { physiological signs, giving patients precise information about their bodies, and } \\
\text { demonstrate which exercises and diets appear to work best for each of them. }\end{array}$ & Evolving \\
\hline Myovolt & Myovolt & $\begin{array}{l}\text { Uses vibration to help boost circulation. The user straps on the device and it delivers } \\
\text { high intensity vibrations to muscle and soft tissue. The device has an approximate } 3 \\
\text { hour battery life and } 70 \text { minute continuous run time. }\end{array}$ & Evolving \\
\hline $\begin{array}{l}\text { National Yang-Ming } \\
\text { University }\end{array}$ & $\begin{array}{l}\text { Wearable rehabilitation } \\
\underline{\text { sensors }}\end{array}$ & $\begin{array}{l}\text { Rehabilitation exercise assessment mechanism using three wearable sensors } \\
\text { mounted on the chest, thigh and shank of the working leg in order to enable the } \\
\text { patients with knee osteoarthritis to manage their own rehabilitation progress. The } \\
\text { system can help patients self-manage their rehabilitation progress, and when the } \\
\text { improper exercise posture is detected, an error alarm can be provided for the } \\
\text { patients to verify their movements in real-time. }\end{array}$ & Evolving \\
\hline Neumitra & $\begin{array}{l}\text { Brain health performance } \\
\text { measuring }\end{array}$ & $\begin{array}{l}\text { Measures the effects of stress on brain health performance in various ways, from } \\
\text { wearable technology to tablet and mobile software and algorithms. Embedded } \\
\text { biomodules continuously measure the autonomic nervous system and mobile } \\
\text { software links contextual data, such as events, locations, and activities, with the } \\
\text { physiology of stress and sleep toward self-managing symptoms and identifying their } \\
\text { causes. }\end{array}$ & Evolving \\
\hline Pebble Technology & $\begin{array}{l}\text { Wearable software and } \\
\text { analytics }\end{array}$ & $\begin{array}{l}\text { Software to make use of wearable data, focused on taking the information the } \\
\text { hardware produces and turning it into something useful for the consumer. }\end{array}$ & Evolving \\
\hline Shepherd Pathways & EyeRemember & $\begin{array}{l}\text { An app that runs on Google Glass in conjunction with Bluetooth low-energy beacons } \\
\text { worn/carried by friends, family, therapists and others in the user's community. When } \\
\text { a person wearing a beacon is within Bluetooth range, a contact information card } \\
\text { appears on the Google Glass. }\end{array}$ & Evolving \\
\hline SUNU & $\underline{\text { SUNU sonar wristband }}$ & $\begin{array}{l}\text { Sonar-equipped wristband designed to help visually impaired users perceive their } \\
\text { environment and avoid obstacles. The device uses sound waves and gentle } \\
\text { vibrations to guide a user. }\end{array}$ & Evolving \\
\hline $\begin{array}{l}\text { Terje } \\
\text { Norderhaug(individual) }\end{array}$ & $\underline{\text { Airport Al }}$ & $\begin{array}{l}\text { Allows travelers at the airport to 'leave trails' and share their experience with fellow } \\
\text { travelers thus providing updated airport traffic information. Employs the indoo.rs } \\
\text { software development kit that features mapping, routing, and analytics capabilities. }\end{array}$ & Available \\
\hline
\end{tabular}


PNNL RTA Monthly Report Appendix A: Technology Summary

\begin{tabular}{|c|c|c|c|}
\hline Toshiba & $\begin{array}{l}\text { TZ1031MBG and } \\
\text { TZ1011MBG application } \\
\text { processors, ApP Lite Internet } \\
\underline{\text { of Things processor }}\end{array}$ & $\begin{array}{l}\text { Sensor-laden processors designed to push wearables further through extended } \\
\text { applications and long battery life.TZ1031MBG and TZ1011MBG application } \\
\text { processor package integrates sensors for data collecting, is able to process data, } \\
\text { includes flash memory for data storage and a Bluetooth controller for data } \\
\text { transmission. }\end{array}$ & Evolving \\
\hline UL Technologies & $\underline{\text { Compliance services }}$ & $\begin{array}{l}\text { A comprehensive service that offers customized product validation, advisory, testing, } \\
\text { risk mitigation, interoperability, and global market access services for wearable } \\
\text { technology products. The services will help to assist manufacturers in supplying } \\
\text { consumers with safer and more reliable wearable products while reducing the time } \\
\text { to market }\end{array}$ & Available \\
\hline Vivametrica & $\frac{\text { Vivametrica health }}{\text { monitoring platform }}$ & $\begin{array}{l}\text { A platform that can be used by the consumer for health management. The platform } \\
\text { features with algorithms and analytics that can be used for research purposes, or to } \\
\text { provide extra services such as additional data monitoring at a rehab clinic, for } \\
\text { example. }\end{array}$ & Evolving \\
\hline Wicab & BrainPort & $\begin{array}{l}\text { A small video camera mounted to sunglasses connected via an electrical cord to a } \\
\text { mouthpiece with a grid of } 400 \text { electrodes. The digital information from the video is } \\
\text { translated into electrical stimulated bubble-like patterns on the tongue that represent } \\
\text { shape, size, location, and motion of things in their environment. }\end{array}$ & Evolving \\
\hline Xsens & MVN Biomech & $\begin{array}{l}\text { Full-body suit or strap-based system that transforms 3D human motion tracking into } \\
\text { a wearable technology allowing users to visualize motion patterns. The system } \\
\text { channels wireless sensor data through biomechanical models and sensor fusion } \\
\text { algorithms before visualizing them in real-time in Xsens' own MVN Studio Biomech } \\
\text { software or in application-specific packages. }\end{array}$ & Available \\
\hline
\end{tabular}





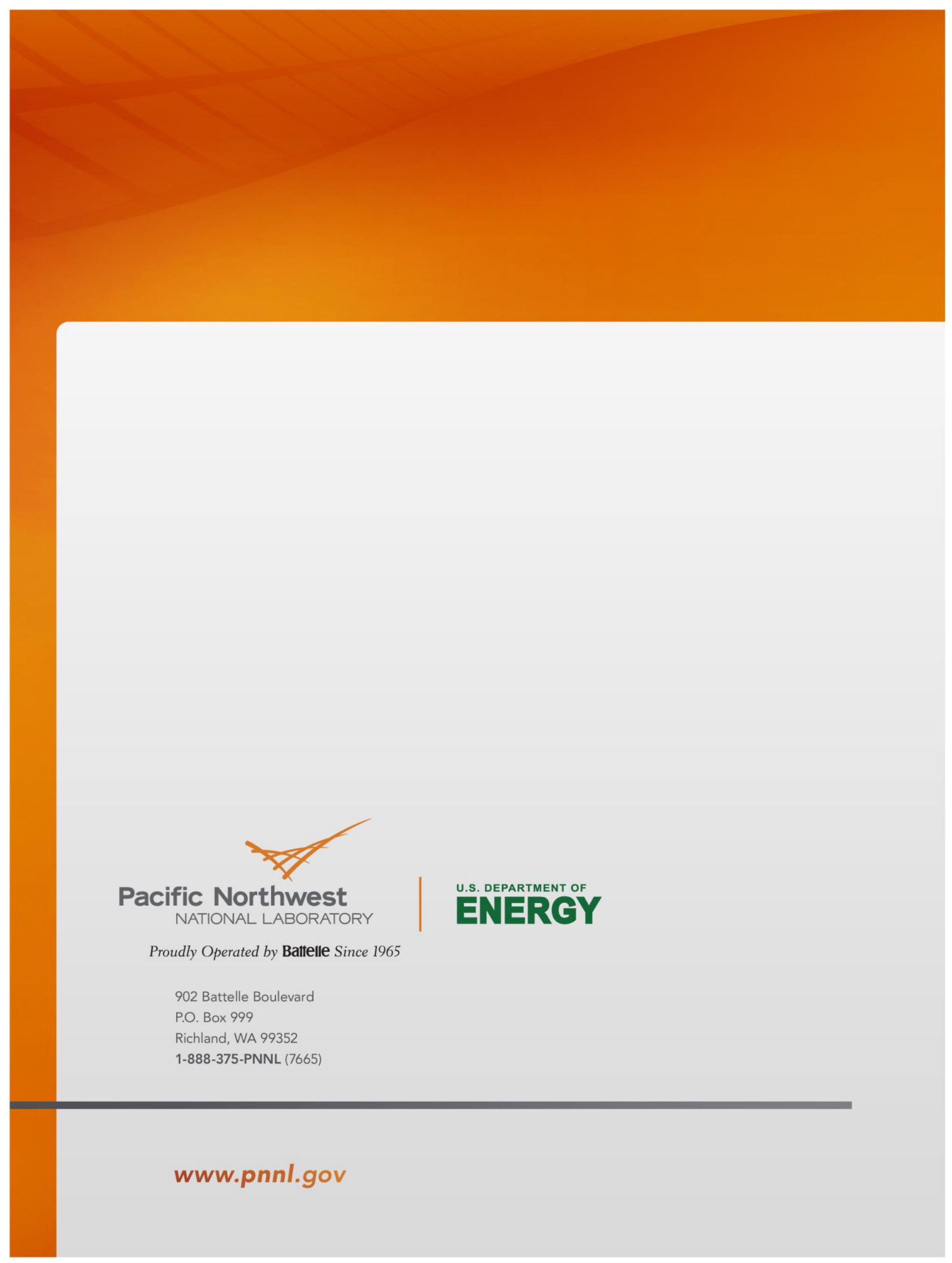

